\title{
Glimpses of Einstein and His Philosophy
}

\author{
Dr. (Prof.) V.C.A. Nair \\ Educational Physicist and Research Guide for Physics at JJT University, Rajasthan, India
}

\begin{abstract}
The paper contains glimpses of rather a brief review of Albert Einstein right from his childhood till his death. The subject matter of the paper is revised version of what the author delivered as a lecture on the $106^{\text {th }}$ birth anniversary of the scientist to the faculty of an eminent institution in Mumbai, India. It is difficult to give only just glimpses of a great scientist like Albert Einstein. But, what I have presented in the paper with large number of diagrams, quotes and statements numbering more than 100 made by Einstein, the reader will find it to be exhaustive making it really a treatise rather than a simple treatment.
\end{abstract}

Keywords: Einstein effect, Einstein shift, Gravitational deflection of light, Perihelion of planet mercury, Photoelectric effect, Quotes of Einstein, Relativity, Theory of gravitation.

\section{INTRODUCTION}

Preamble: This Research Paper is prepared out of a lecture I delivered on $14^{\text {th }}$ March 1985 coinciding with the $106^{\text {th }}$ birth anniversary of Albert Einstein to the members of the teaching faculty of Shri Bhagubhai Mafatlal Polytechnic, Mumbai-400 056, India an eminent institution of its kind in the country. As the audience was multi-disciplined, the subject matter of the lecture was general and not exhaustive to suit a common man, brief and precise enough to complete in one hour. I converted the contents of the lecture with some additions and brought out this Research Paper in such a way that it is made more Physics oriented. The quotations and statements given by Einstein are not deleted from the lecture. In fact as more information is added, the paper has become more exhaustive. As a picture speaks thousand words, photographs of Einstein and some important scientists are also added at appropriate places. Author

Principal, Prof. H.C. Patel ${ }^{@}$ and my colleagues,

Wish all you a very good afternoon. I would like to present to you few glimpses of the great scientist, Albert Einstein and his philosophy today coinciding with his $106^{\text {th }}$ birth anniversary. There is less time at our disposal to give a detailed life sketch of the scientist and elaborate the theories discovered by him.

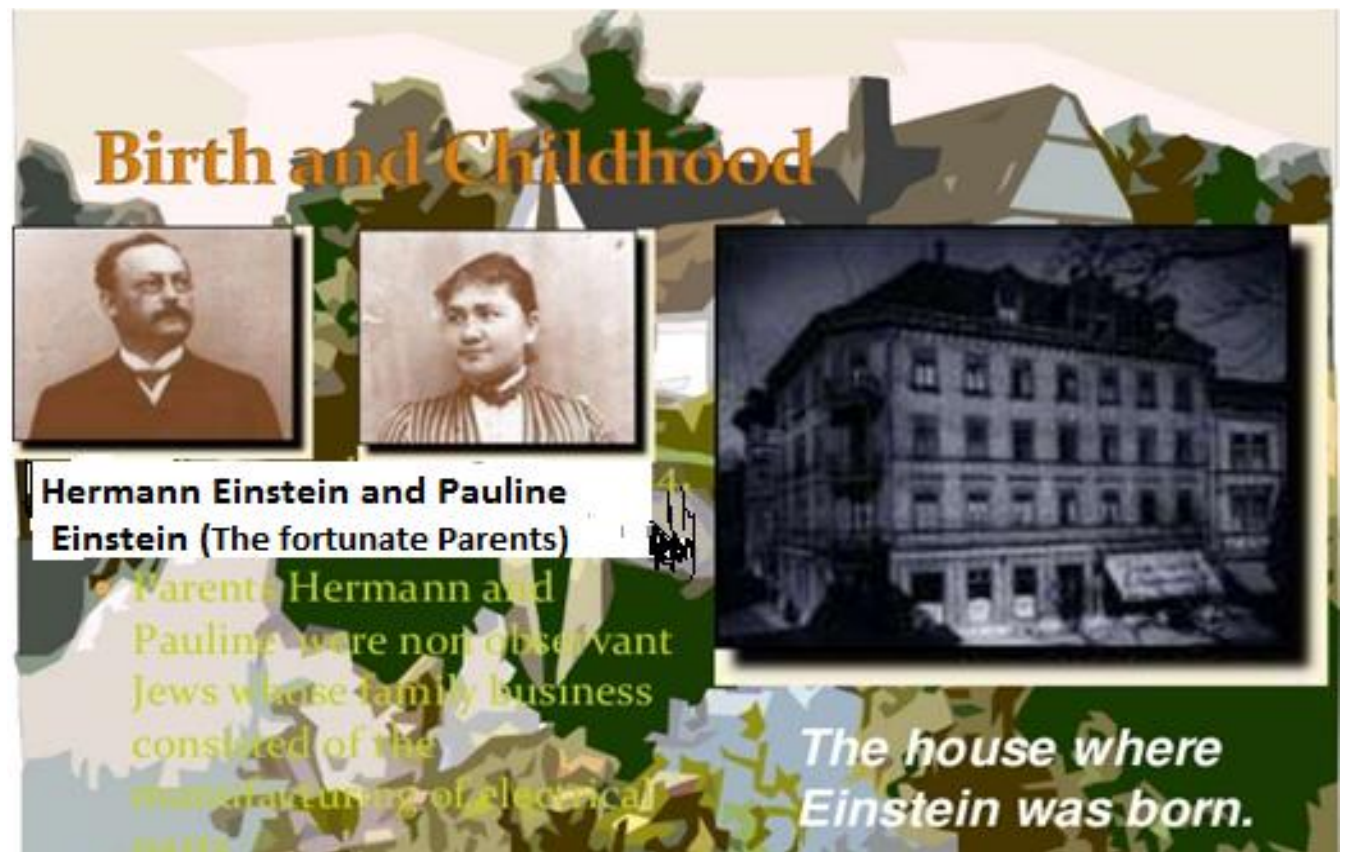

Fig. 1.Einstein's parents and the apartment in the building (right) at Ulm where Einstein was born

@ Principal, Shri Bhagubhai Mafatlal Polytechnic, Mumbai, India 
To begin with, I shall give a brief description of the scientist and his works and a major part of the time I would like to devote in showing you on the Over Head Projector (OHP) the various philosophical statements made by him. I request you to read between the lines of those statements and think deeply on the meanings underlying those statements so that you may be virtually taken to a different world.

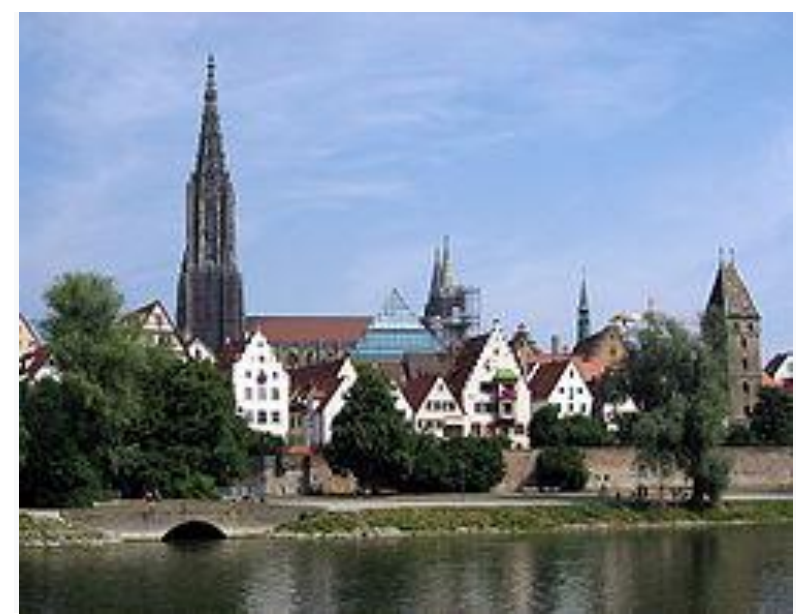

Fig.2.The Swabian city nestled along the Danube (With the Ulm Minster clearly seen)

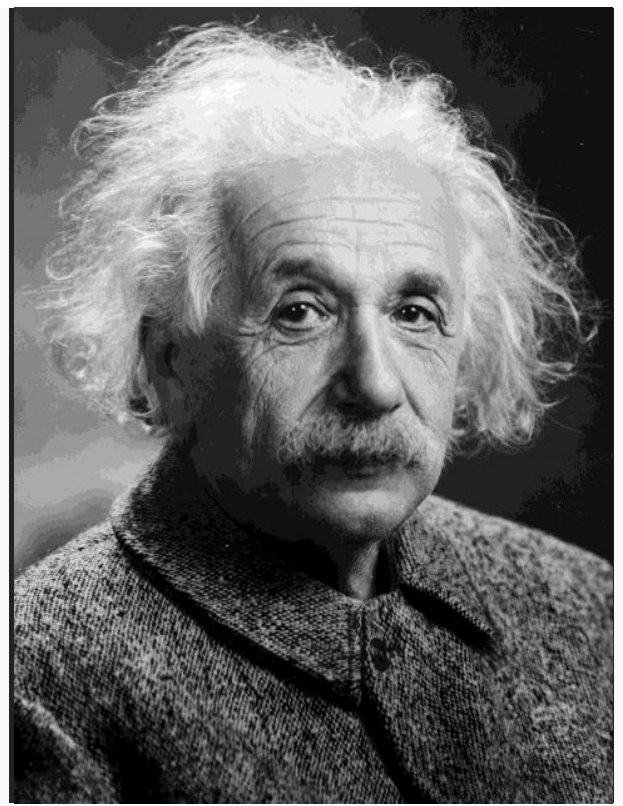

Fig.4 Albert Einstein (1879-1955)

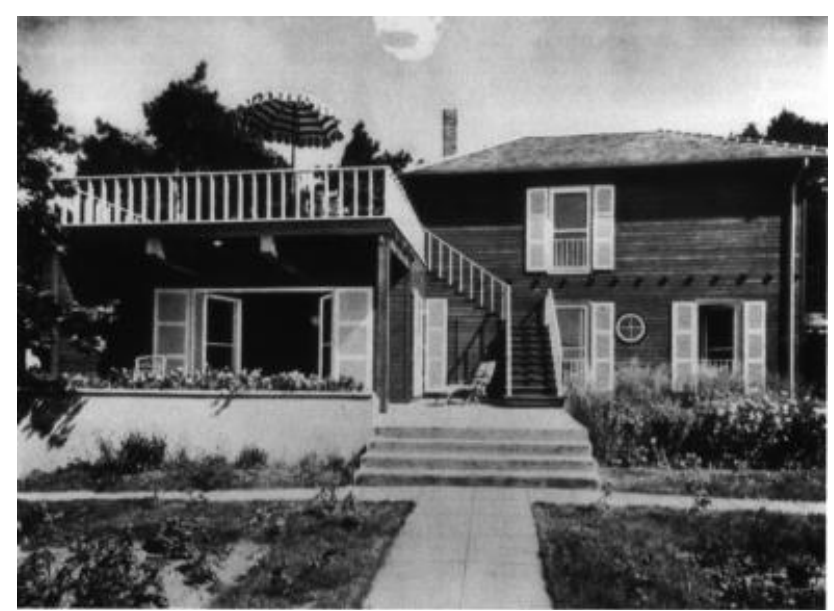

Fig.3 Einstein's Summer house at Caputh near Berlin

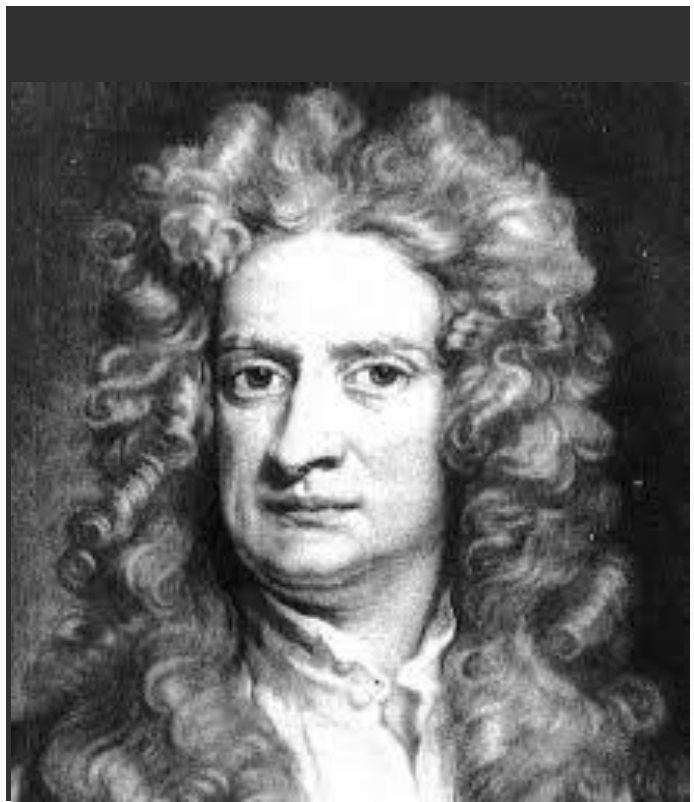

Fig.5 Sir Isaac Newton (1643-1727)

Conclusively at the end of my lecture, I would like to show some photographs of Einstein on the OHP.

On Friday the $14^{\text {th }}$ March 1879 at Ulm, (Fig.1) an old German town on the left bank of the Danube river at the foothills of the Swabian Alps a child was born at 11.30 AM to Jewish parents, Hermann Einstein and Pauline Einstein and the world never knew that this child, a son (Fig.6) born to this parents will ever turn out to be a wonder man and universal wizard ranking as the topmost physicist of the twentieth century by bringing out the theory of Relativity which revolutionized the scientific community as a whole.

The child is Albert Einstein (Fig.4) who grew up with his parents and when the boy could not speak properly even though he attained the age of nine, his parents suspected some physiological deformity in him, but later, the entire world was astonished when this boy till his death in 1955 spoke of Physics, Mathematics, Astronomy, Cosmology and Philosophy, thereby recognizing as the most renowned Mathematical Astrophysicist next only to Sir Isaac Newton.(1643-1727) (Fig.5) 


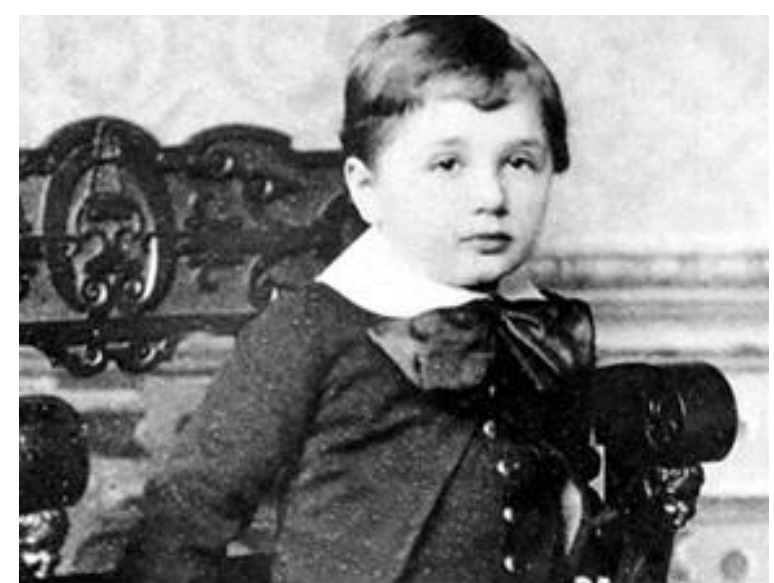

Fig.6 Albert Einstein as a young boy, 4 years
Fig.7. 26 year old Einstein reading his paper in

1905 at Bern

I have referred B Kuznetsev [5] for most of the matter that follow.

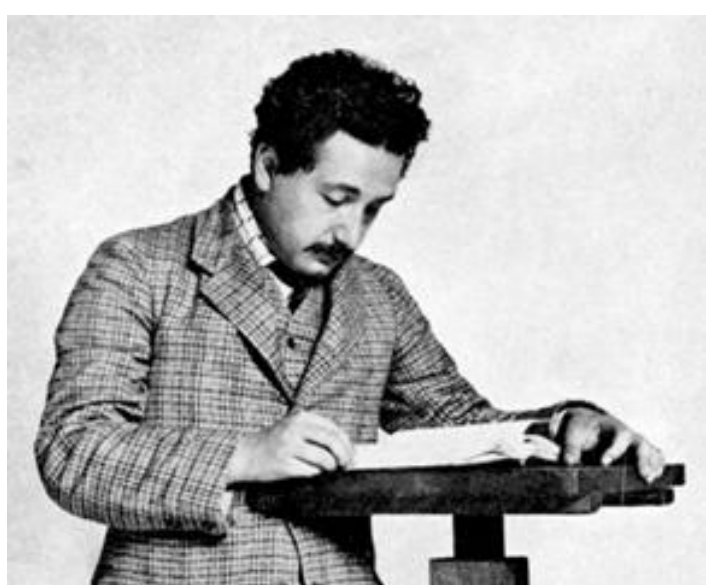

In the year 1905, Einstein was only 26 year old when he published two papers (Fig.7) that greatly contributed to the twentieth century revolution in Physics and Technology. One of the paper was pertaining to the explanation of the Photoelectric Effect. A phenomenon discovered by Heinrich Hertz in 1887 and the explanation on the same based on the classical theory was not satisfactory. An illustrative sketch of photoelectric effect is shown in Fig. 8 Einstein considered the incident light to be a bunch of hypothetical particles which he named as 'Photons' and when they are made to fall on a metal surface, electrons from the atoms of the metal are ejected with kinetic energy (KE). The ejected electrons, Einstein called them as 'Photo-electrons'. The equation governing this phenomenon is,

$$
(\mathrm{KE})_{\max }=\mathrm{h} v-\Phi=\frac{1}{2} \mathrm{~m} \mathrm{~V}^{2}
$$

where $\mathrm{h}$ is the Planck's constant, $\mathrm{m}$ the mass of the electron, $\mathrm{V}$ the velocity with which the electron is ejected from the metal and $\Phi$ Einstein called it as the work function meaning thereby the energy required to extract the electron from the metal. The above equation is a very simple algebraic equation compared to the very complicated mathematical equations using Tensor Calculus in the later theories developed by Einstein. But the equation worked wonders as it was later used by physicist, R A Millikan to calculate the value of the Planck's constant to be $6.62 \times 10^{-34}$ Joule second. It proved as a triumph for the Quantum theory of Max Planck put forward in 1901. Moreover, it has tremendous applications in science and technology and Einstein was awarded Ph.D by University of Zurich for this discovery.

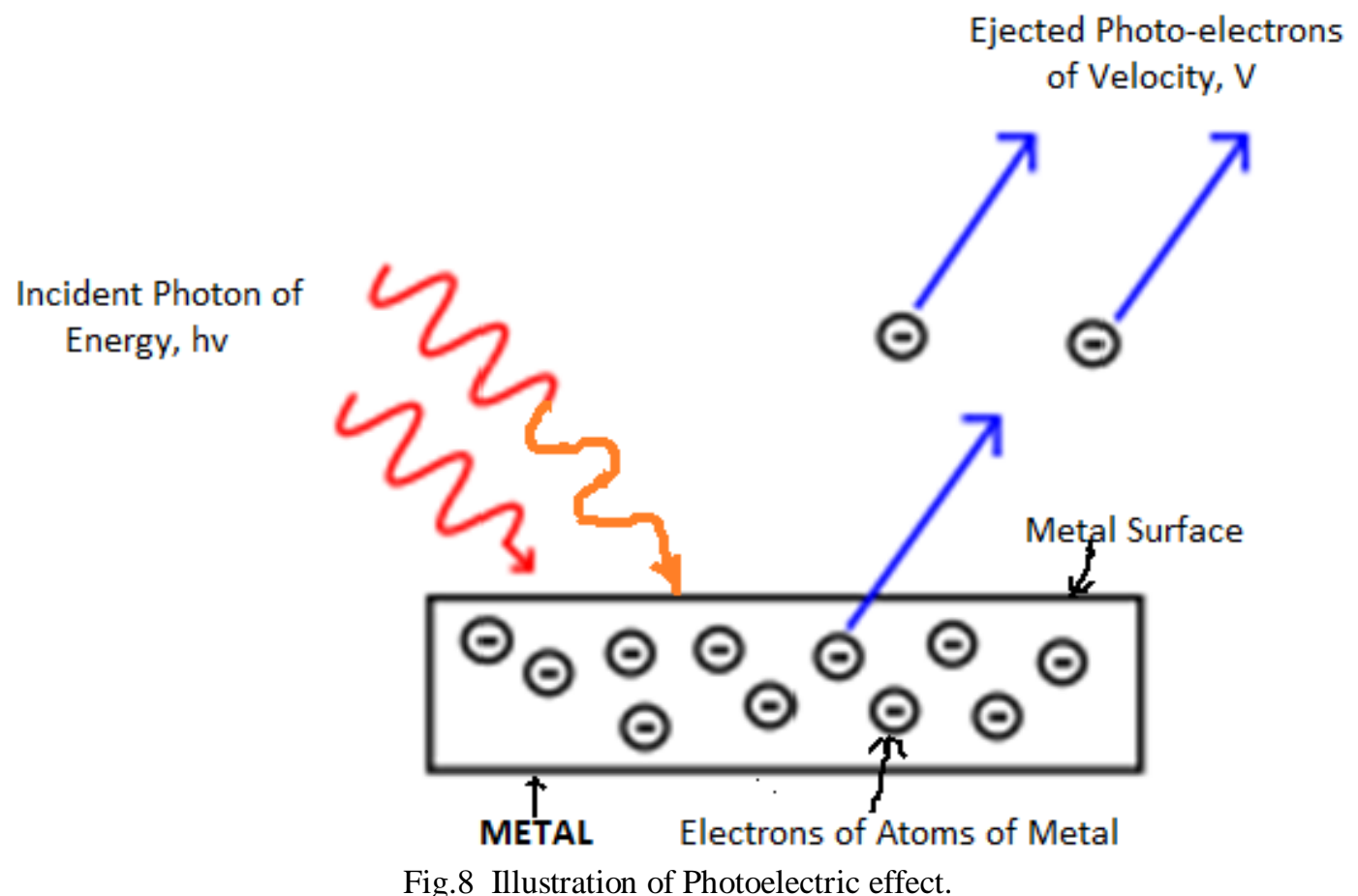


The other paper read by Einstein in the same year described the Special Theory of Relativity in which the variation of mass with velocity and the famous equation, $\mathrm{E}=\mathrm{m} \mathrm{c}^{2}$, where $\mathrm{E}$ is the energy, $\mathrm{m}$ the mass and $\mathrm{c}$ the velocity of light are dealt with. This eventually led to the development of nuclear energy and explosions. An original manuscript pertaining to this paper is shown in Fig.9.

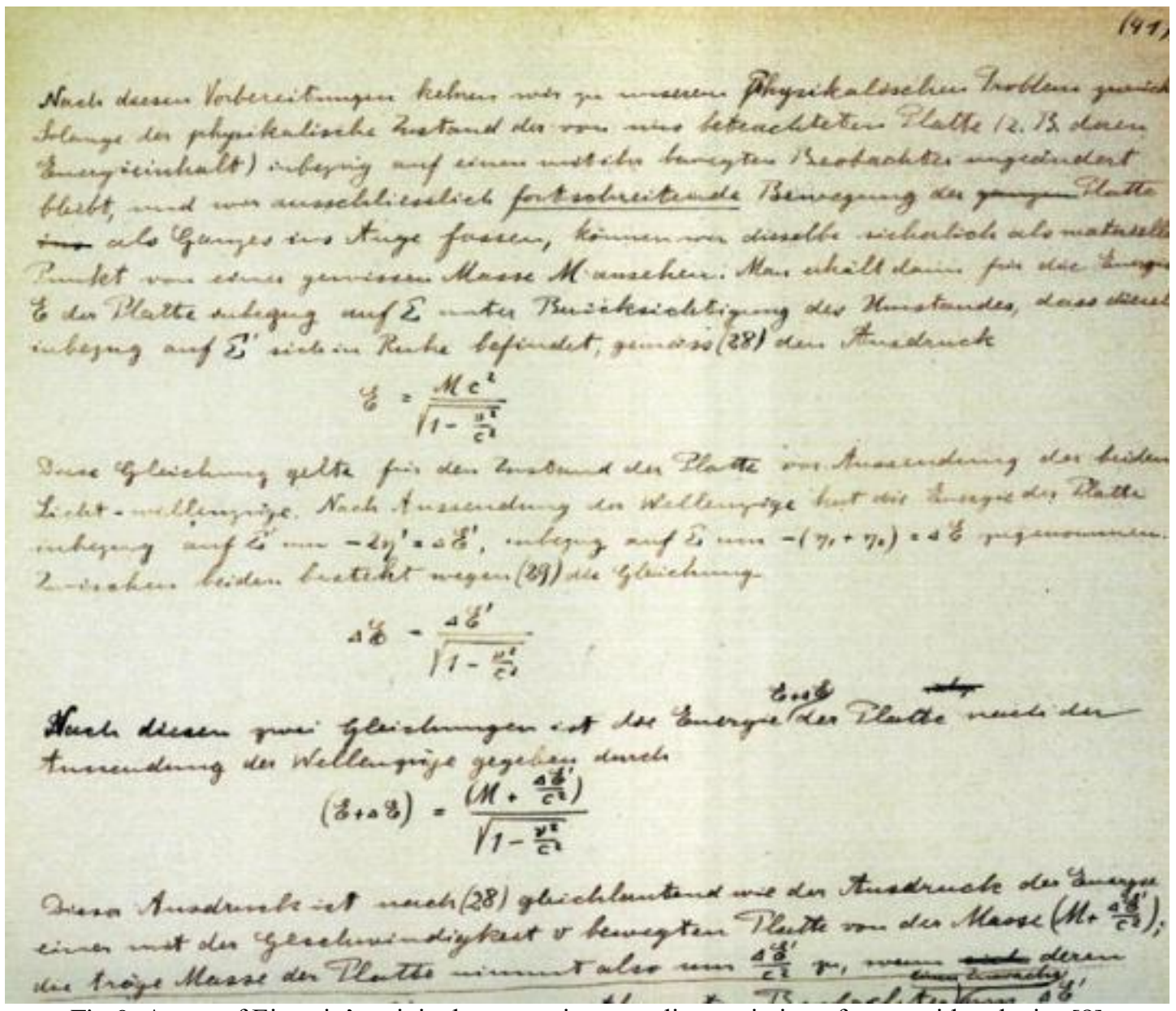

Fig.9 A part of Einstein's original manuscript regarding variation of mass with velocity [8]

Thus, 1905 was Einstein's “Annus Mirabilis” (Miracle Year), never has so much been written in a single year by anybody that impacted a century of scientific growth. The entire world recognized this impact and to commemorate this event, the United Nations declared the year 2005 as the "World Year of Physics".

Einstein's General Theory of Relativity was proposed in 1915 which dealt with gravitation. Newton's theory of gravitation failed to explain the cause of gravitation as is evident from the quotation from his" Letters dated 17 January 1692/3 to an eminent English classical scholar, critic and theologian, 'Richard Bentley' (1662-1742) quoted below:

"You sometimes speak of gravity as essential and inherent to matter. Pray do not ascribe that notion to me; for the cause of gravity is what I do not pretend to know and therefore would take more time to consider of it. ......."

Newton further adds below thus:

"Gravity must be caused by some agent acting constantly according to certain laws; but, whether this agent be material or immaterial I have left to the consideration of my readers".

This evidently indicates that Newton himself was not sure of the cause of gravitation. The general theory of relativity of Einstein expanded Newton's ideas of gravitation by relating gravitational forces to the effects of curvature of space. Einstein gave the following arguments for the cause of gravitation:

"In the absence of material bodies space is homogeneous, but in the presence of material bodies, space becomes curved. It is the homogeneity of space, its 'curvature' that we perceive as gravitation. Gravitation is a manifestation of the space-time properties of the world. The geometry of space is determined by the distribution of bodies in space and geometry in a gravitational field cannot be Euclidian". 
Einstein further argued that:

"Anything that has mass and mass is inherent in all matter must experience gravitational action. There is no exception even for light".

Thus he explained the cause of gravitation by discovering one of the great mysteries of nature.

For an extensive and descriptive treatment, readers should refer J.B. Rajam [7]

According to Einstein, "A quantum of light should have both inertial and gravitational mass. Since mass distorts space-time continuum, a ray of light passing close to the Sun should be deflected slightly towards the Sun".This is the famous 'Einstein Effect'. The diagram pertaining to this is shown in Fig.10.

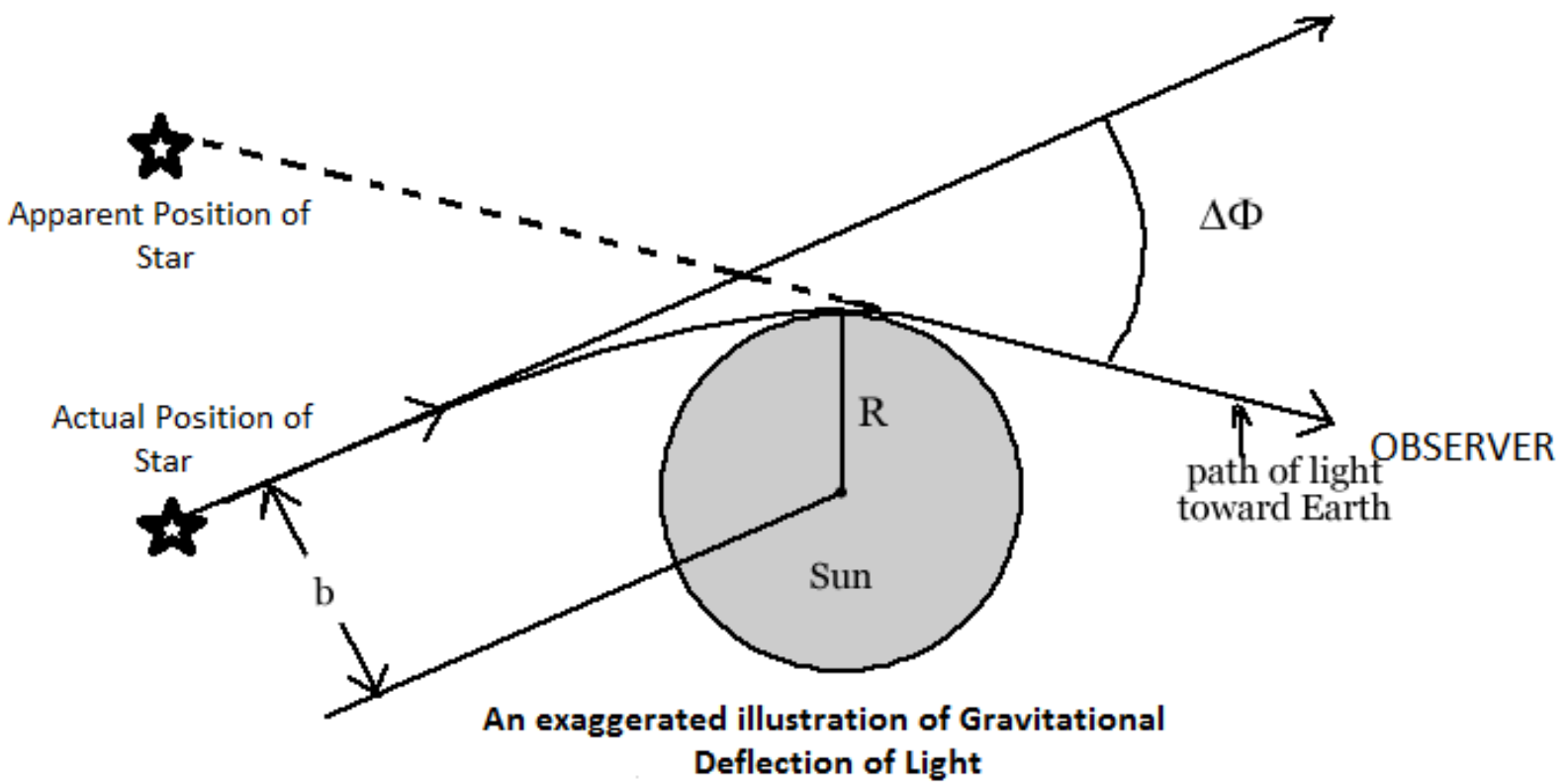

Fig.10 Illustration of Einstein Effect

The measurement of the shift is to be carried out during a total eclipse of the Sun as the intensity of the Sun is considerably less. During a total eclipse of the Sun, the light from a distant star gets deflected as shown in the fig. and apparently appears in a different position as shown. Einstein obtained a formula for the angle of deflection, $\Delta \Phi$ after some rigorous Mathematics as,

$$
\Delta \Phi=\frac{4 \mathrm{G} \mathrm{M}}{\mathrm{c}^{2} \mathrm{R}}
$$

where $\mathrm{G}$ is the Newton's constant of gravitation, $\mathrm{M}$ the mass of the Sun $\mathrm{R}$ the radius of the Sun and c the speed of light. A calculation using this formula by a physics enthusiast Don Edwards [3] and Christian Magnan [2] is given below:

$$
\Delta \Phi=\left(\frac{4 \mathrm{G} \mathrm{M}}{\mathrm{c}^{2} \mathrm{R}}\right)=\left(\frac{4 \times 6.67 \times 10^{-11} \times 2 \times 10^{30}}{\left(3 \times 10^{8}\right)^{2} \times 7 \times 10^{8}}\right)=8.47 \times 10^{-6} \text { radians }=1.75 \text { arc second }
$$

Such measurements were carried out during the total eclipse of the Sun in the years 1919, 1922, and years whenever and wherever there used to be a total solar eclipse. Sir Arthur S. Eddington, a world renown British astronomer, a close associate of Einstein and one of the few who has understood the theory relativity and assisted by Astronomer Royal of Britain, Sir Frank Watson Dyson was the leader of the 29 May1919 astronomical expedition to South Africa to observe and verify the Einstein effect. The value of the shift was found to be 1.74 second in full agreement with Einstein's theory. When Einstein was informed about the success of his theory and asked to comment on it, Einstein replied: "I would have been very much surprised only if otherwise".

Another important experimental confirmation of Einstein's gravitational theory is the advance of the perihelion of planet Mercury. According to Einstein, the space near a heavy mass is curved so that any body which enters this space travels in a curved path. The curvature of space increases closer the body approaches the heavy mass. The orbits of planets around the Sun are explained on this basis. For relatively distant planets whose orbits are nearly circular, the Einstein law of gravitation reduces to the Newtonian inverse square law. But, in the case of planet Mercury which is very close to the Sun, the orbit is very eccentric, so that Einstein's law departs sufficiently from Newton's law for the two to give results divergent enough for an experimental test. 


\section{International Advanced Research Journal in Science, Engineering and Technology} ISO 3297:2007 Certified

Vol. 4, Issue 9, September 2017

In an elliptical orbit, a point near to the Sun on the major axis is called the perihelion. As a result of attraction between various planets of the solar system, the major axis slowly rotates thereby causing a precession of the perihelion around the Sun. This is called the "Advance of the Perihelion". (Fig.11) Astronomers have calculated this rate of precession as 574 seconds of arc per century. Calculations based on Newton's theory could give only 531 seconds of arc per century so that a difference of 43 seconds is left over.

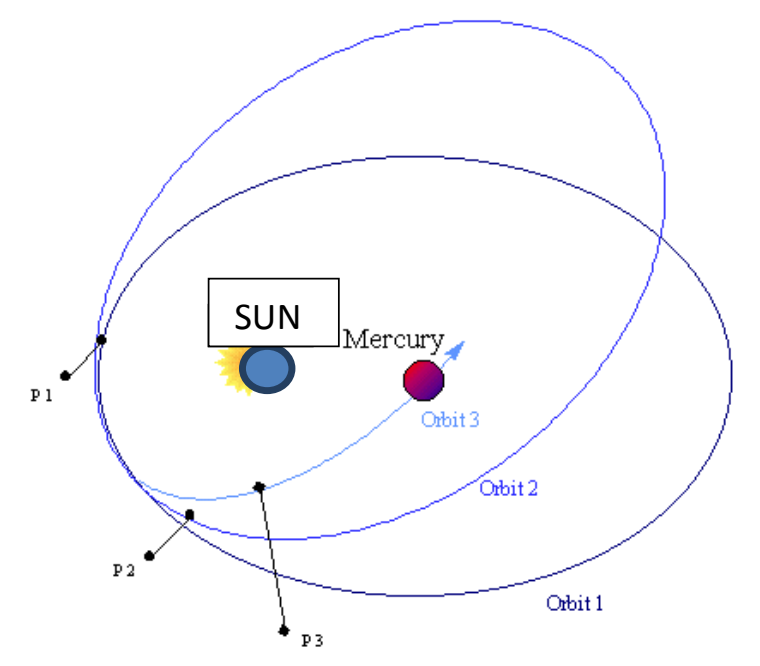

Fig 11 The precession of Perihelion of planet Mercury

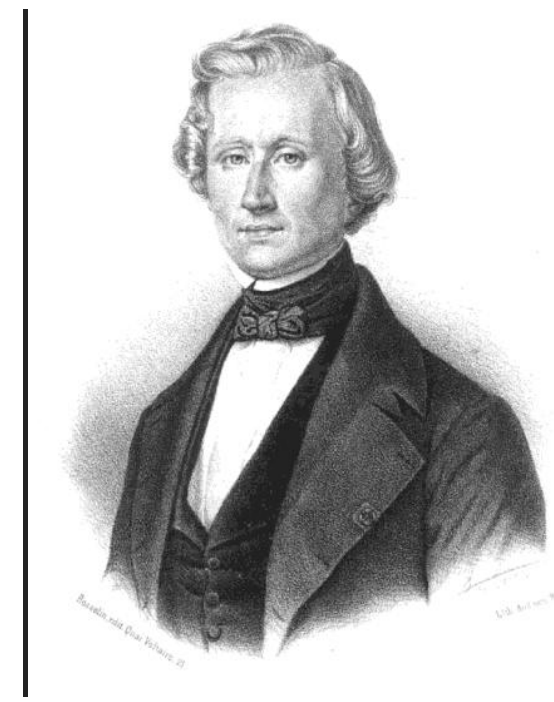

Fig.12 Urbain Le Verrier (1811-1877)

Forming a Rosetta-type motion

A French mathematician, Urbain Le Verrier (Fig.12) following Newton's theory of gravitation and who discovered planet Neptune with a mere stroke of his pen, said that the advance of the perihelion of Mercury is due to the presence of an yet to be discovered planet in the solar system. He even named this planet as "Vulcan" Astronomers failed to discover Vulcan and argued that some asteroid field or massive field of dust adding mass to Mercury and that might be the reason for the discrepancy.

On 18 November 1915, Einstein solved the mysterious motion of Mercury by using the vacuum field equations. . He disposed planet Vulcan as imaginary and successfully accounted for the difference by showing that the orbit of a planet is a Kepler orbit only to a first approximation. In the rigorous mathematical treatment using Tensor calculus, Einstein obtained an additional term $\delta$ for the extra rotation in radians per orbit as shown below [1]:

$$
\delta=3 \pi\left[\frac{\mathrm{R}_{\mathrm{s}}}{\mathrm{a}\left(1-\varepsilon^{2}\right)}\right]
$$

where $R_{s}$ is the Schwarzschild radius of the Sun, a the length of the semi major axis of planet Mercury and $\varepsilon$ the eccentricity of the elliptical orbit. In terms of the period T of Mercury's orbit and velocity of light c, the equation gets expanded to:

$$
\delta=\left[\frac{24 \pi^{3} \mathrm{a}^{2}}{\mathrm{c}^{2} \mathrm{~T}^{2}\left(1-\varepsilon^{2}\right)}\right]
$$

Substituting the values, we get

$$
\delta=\left\{\frac{24 \times(3.1412)^{3} \times(57.9)^{2}}{(299792458)^{2} \times(7600530.24)^{2} \times\left[\left[1-(0.205636)^{2}\right]\right.}\right\}=42.98 \approx 43 \text { seconds of arc/century }
$$

This, indeed, is a remarkable success for the gravitational theory of Einstein.

One more important test for the verification of Einstein's theory of gravitation is the "Shift of Spectral lines" known as the "Red Shift". When light moves away from a strong gravitational field, its frequency should be slightly diminished or its wavelength slightly increased due to the work done by the light quantum against the attractive force at the expense of its own energy content. As a result the , the spectral lines given out by the Sun will be slightly displaced towards the red end of the spectrum. This displacement of the Fraunhoffer lines is known as "Einstein Shift". It is calculated and found to be 0.01 Angstrom unit for a line of 5000 Angstrom unit. By the calculations of the redshift method, one can arrive at the radius of distant stars. The binary Pulsar PSR $1916 \pm 16$ discovered in 1975 is found to have a perihelion advance of 4.23 degrees per year. 
UGC Approved Journal

Vol. 4, Issue 9, September 2017

A part of Einstein's original manuscript on gravitation is shown in Fig.13 [8]

In addition to what I gave above, I am purposely avoiding topics such as Brownian Motion, the EPR (EinsteinPodolsky-Rosen) Paradox the quantum entanglement wherein Einstein's name is involved in the explanation of those topics so as to maintain brevity of this paper. The readers will, however, miss their glimpses over these.

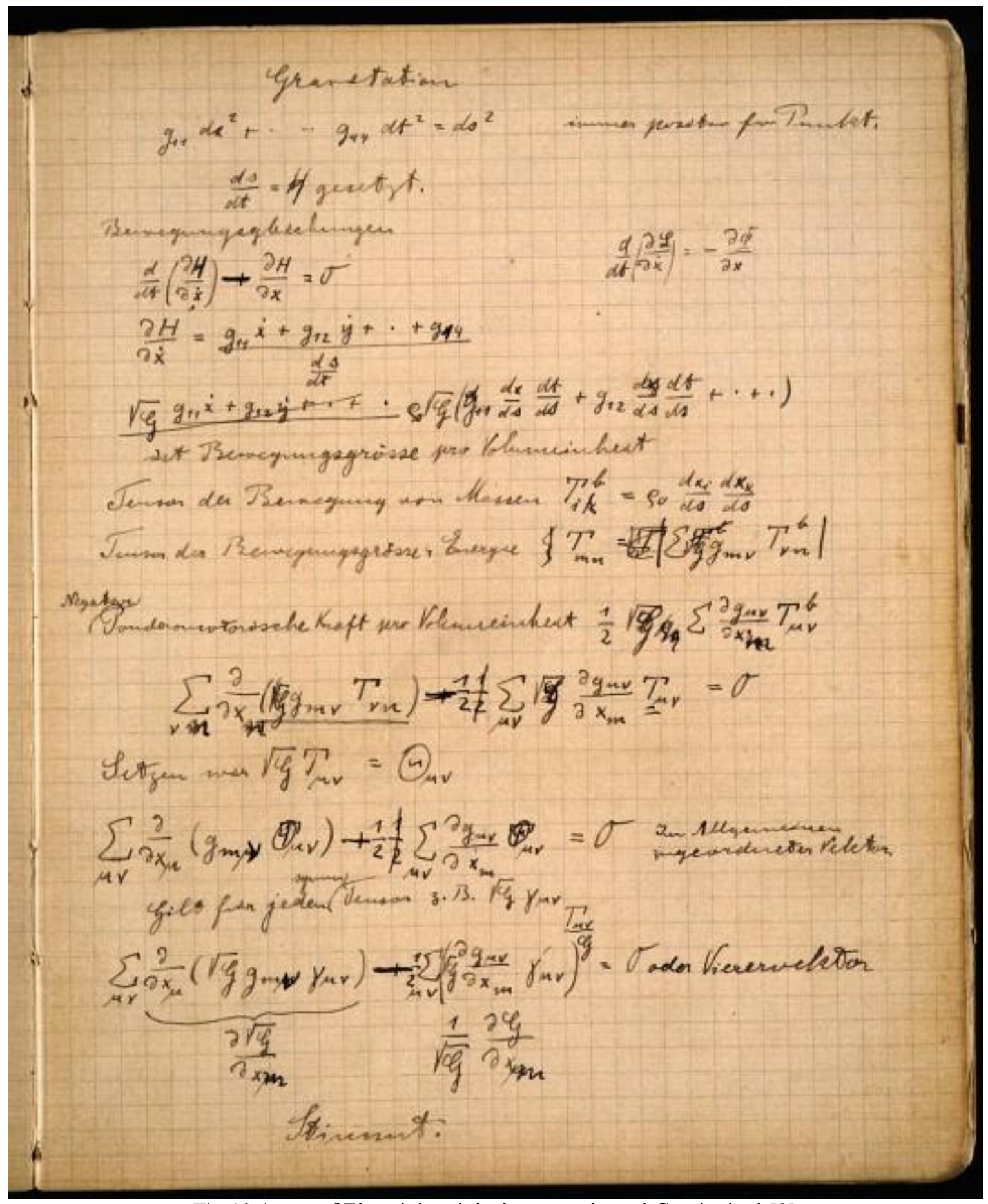

Fig.13 A part of Einstein's original manuscript on' Gravitation' [8]

(At the start, as a heading he has written 'Gravitation' and at end at bottom he writes as 'It's correct)

Einstein is generally known as a great theoretical physicist, but in the earlier days of his career, he was also an experimentalist. In Fig.14 is shown a laboratory at Zurich's Technische Hochschule where he used to carry out experiments. 


\section{International Advanced Research Journal in Science, Engineering and Technology}

ISO 3297:2007 Certified

Vol. 4, Issue 9, September 2017

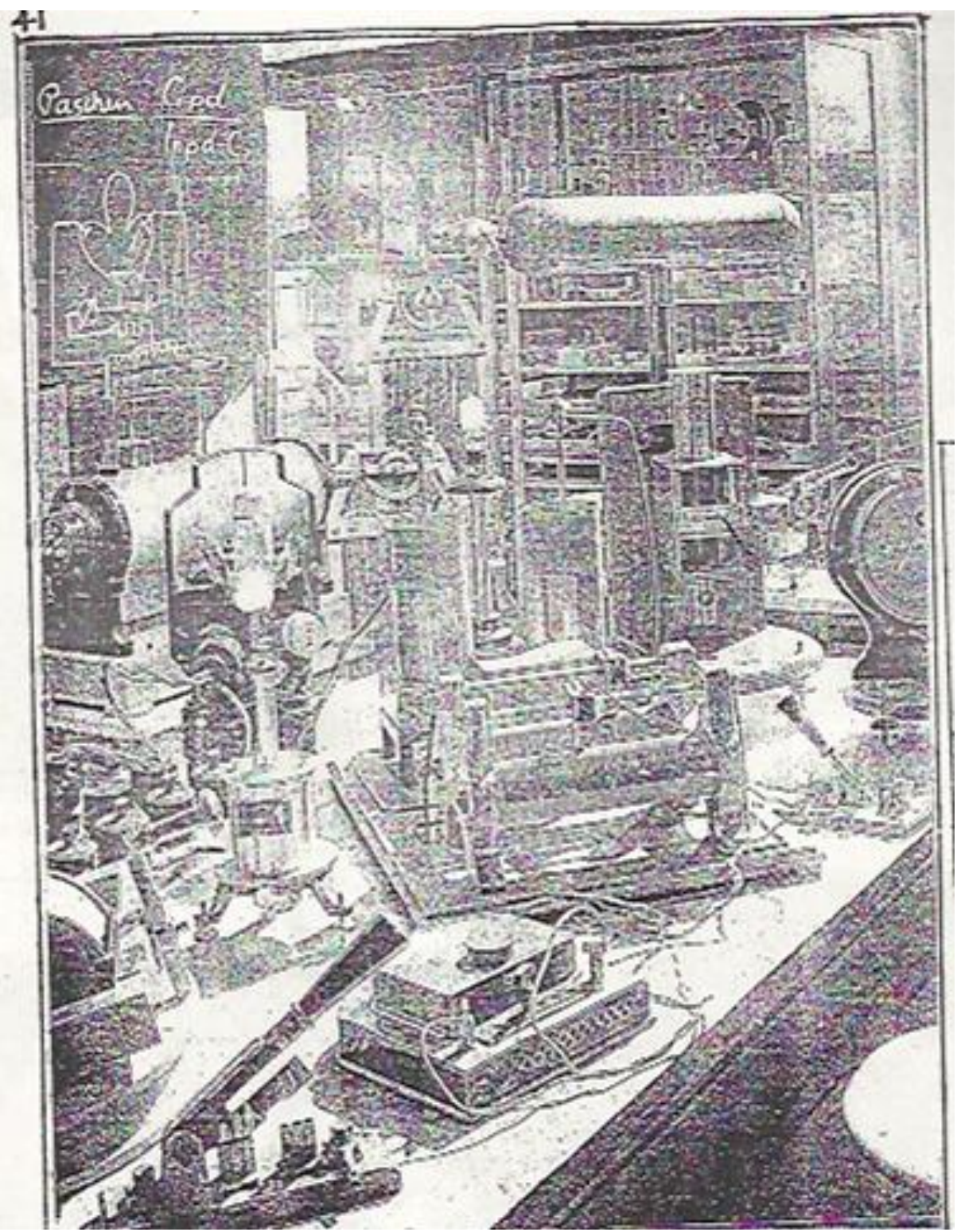

Fig.14 The Laboratory in Zurich where Einstein carried out experiments

The following are some of the philosophical statements including quotations numbering nearly 100 made by Einstein during his lifetime I am giving them in italics. A large number of quotes are given by Joel Brown [4]. As a matter of caution, I would like to point out to the readers that I have not separated the quotes from statements.

Einstein writes in his autobiography:

- "In a man of my type the turning point of the development lies in the fact that gradually the main interest disengages itself to a far reaching degree from the momentary and merely personal and turns towards the striving for a mental grasp of things".

- "Joy in looking and comprehending is nature's most beautiful gift".

- "The formulation of patent statements was a blessing. It gave me the opportunity to think about Physics. Moreover, a practical profession is a salvation for a man of my type: an academic career compels a young man to scientific production and only strong characters can resist the temptations of superficial analysis".

- "Unthinking respect for authority is the greatest enemy of truth".

- "Try not to become a man of success, but rather try to become a man of value".

- "Not everything that can be counted counts, and not only everything that counts can be counted".

- "A man should look for what he is, and not for what he thinks should be".

Einstein writes about the response to his paper on Relativity published in the year 1905: 


\section{International Advanced Research Journal in Science, Engineering and Technology} ISO 3297:2007 Certified

Vol. 4, Issue 9, September 2017

- "I am approaching the age when one deplores the revolutionary spirit of youth".

- "The most incomprehensible thing about the world is that it is comprehensible. The comprehensibility of physical reality appears as 'wonder' because it finds expressions not in logical verbal constructions but in the history of Science, in the history of Technology, which reveals the way in which man cognizes and comprehends the world in all its complexity".

- "The man who regards his own life and that of his fellow creatures as meaningless is not merely unhappy but hardly fit to live."

- "I cannot conceive of a God who rewards and punishes his creatures Neither can nor I, nor would I want to conceive of an individual that survives his physical death, let feeble souls from fear or absurd egoism, cherish such thoughts"”

- "Without the conviction of rationality of reality and its accessibility to human mind, science degenerates into soulless empiricism".

- "What I dislike ........... is the basic positivistic attitude, which from my point of view is untenable, and which seems to me to the same thing as Berkeley's principle, esse est percipi".

- "Conviction that the external world exists independently of the observer investigating it constitutes the basis of the whole science of nature".

- "In scientific thinking, there is always the poetic element. The appreciation of good science and appreciation of good music demand, in part, similar mental processes".

- "All religions, arts and sciences are the branches of the same tree".

- "In the middle of a difficulty lies opportunity".

- A person who never made a mistake, never tried anything new".

- "Whoever is careless with the truth in small matters, cannot be trusted in important matters".

- "I speak to everyone in the same way whether he is the garbage man or the president of the university".

- "The value of man should be seen in what he gives and not in what he is able to receive".

In a letter to Max Born, a contemporary physicist, Einstein wrote:

- 'It is every man's duty to be a model of integrity and have the courage seriously to uphold one's ethical convictions in the company of cynics. For many years I have striven to act accordingly - with varying success".

- "The advancement of science represents a fight from both 'wonder' and 'self-evidence'. Science strips geometrical constructions of self-evidence when experiments find fault in the observations which had given those constructions an apparently sound physical meaning. This is the flight from self-evidence. But then science correlates new observations to pure logical constructions. The former cease to arouse wonder, the latter acquire physical meaning which could not have been gained by pure thinking alone".

During a lecture in the year 1933 on the method of Theoretical Physics, Einstein gives a piece of advise, thus:

- "If one wants to find out anything from the physicists about the methods they use, one should not listen to their words, but fix one's attention to their deeds".

Men asked 'What is the geometry of the real world? Einstein first analyses Helmholtz's answer:

- "The concepts of Geometry are based on real objects and, in the final analysis, geometrical statements are statements about real bodies".

Einstein suggests that:

- "Elegance should be left to the tailors and shoe makers".

- "Wherever it is possible, learning must become living, and this principle will predominate in future reforms of school teaching".

Characterizing Physics as it presented itself when he was a student, Einstein writes:

- "In spite of all fruitfulness in particular, dogmatic rigidity prevailed in matters of principles. In the beginning (if there was such a thing), God created Newton's laws of motion together with the necessary masses and forces. This is all; everything beyond this follows from the development of appropriate mathematical methods by means of deduction".

Einstein writes:

- "A theory is the most impressive the greater the simplicity of its premises is, the more different kinds of things it relates, and the more extended is its area of applicability. Therefore, the deep impression which classical thermodynamics made upon me. It is the only physical theory of universal content concerning which I am convinced that, within the framework of applicability of its basic concepts, it will never be overthrown". 
Einstein adds further:

- "The theory of relativity is characterized, among other things, by the epistemological point of view. There are no concepts in Physics whose usage is necessary or can be justified by a priori considerations. A concept acquires right of existence only by virtue of its clear and unambiguous connection with phenomena and accordingly, with physical reality. In the relativity theory, such concepts as absolute simultaneity, absolute velocity, absolute acceleration, etc. are rejected as they have no unambiguous connections with experience.............. It was necessary to define every physical concept in such a way so as to be able (in every specific case) to decide in principle whether it corresponds to reality or not".

- "Hate is presumably a privilege of the 'cultured' who have the time and energy for it and who are not the slave of Care".

In a conversation with James Frank, Einstein once said:

- "I sometimes ask myself: How did it come that I was the one to develop the theory of Relativity? The reason, I think is that a normal adult never stops to think about problems of space and time. These are things which he has thought of as a child. But my intellectual development was retarded as a result of which I began to wonder about space and time only when I had already grown up. Naturally, I would go deeper into the problem than a child with normal abilities".

- “Applied to Maxwell's equations, the principle of relativity requires, in particular, the mass to be a direct measure of a body's energy; light carries mass. A fascinating and intriguing idea. I only wonder if God might not just be jesting and making a fool of me".

- "If the interval between two events at two different points is less than the time needed for light to span the distance between them, then these events are not facts in the history of any one immutable thing".

Einstein once playfully remarked:

- "The people in Gottingen sometimes strike me, not as if they wanted to help one formulate something clearly, but as if they wanted only to show us physicists how much brighter they are than me".

In an article published in the London Times on 28 November 1919, Einstein wrote:

- "Here is yet another application of the principle of Relativity for the delectation of the reader: Today, I am described in Germany as a German Savant, and in England as a Swiss Jew. Should it ever be my fate to be represented as a bete noire, I should on the contrary become a Swiss Jew for the Germans and a German Savant for the English".

- "My pacoifism is an instinctive feeling a feeling that possesses me because that the murder of man is disgusting. My attitude is not derived from any intellectual theory but is based on my deepest antipathy to every kind of cruelty and hatred. I might go on to rationalize this reaction, but that would really be a posteriori thinking".

- "The ideals which have lighted my way, and time after time have given me new courage to face life cheerfully, have been Kindness, Beauty and Truth. Without the sense of kinship with men of like mind, without the occupation with the objective world the eternally unattainable in the field of art and scientific endeavors, life would have seemed to me empty".

- "When the time comes to preserve life, then we have to fight back".

- "Everyone who is seriously involved in the pursuit of science becomes convinced that a spirit is manifest in the laws of the universe - a spirit vastly superior to that of a man and one in the face of which we with our modest powers must feel humble".

In a letter to physicist Max Born in 1944, Einstein said:

- "You believe in the dice-playing God and I in the perfect rule of law in a world of something objectively existing".

- "Everybody is a genius. But, if you judge a fish by its ability to climb a tree, it will live its whole life believing that it is stupid".

In the year 1938, Einstein wrote in a letter to Maurice Solovine, a Romanian studying philosophy at the university of Bern:

- "Men are more influenced by suggestions than horses, which is why they have a fashion for every period, the majority being quite unaware of its origin".

Einstein, the greatest physicist in the world told physicist Leopold Infeld in Princeton:

* "Physicists consider me as an old fool, but, I am convinced that the future development of Physics will depart from the present road".

In 1932, Einstein had a meeting with Philip Frank, his long-time scientific colleague in Berlin where he remarked about Quantum Statistical Mechanics as follows: 
- "A new fashion has arisen in Physics. By means of ingeniously formulated theoretical experiments, it is proved that certain physical magnitudes cannot be measured, or, to put it more precisely, that according to accepted natural laws the investigated bodies behave in such a way as to baffle all attempts at measurement. From this the conclusion is drawn that it is completely meaningless to retain these magnitudes in the language of Physics. To speak about them is pure metaphysics".

- "Man must be educated to react delicately; he is to acquire and develop intellectual muscles; And the method of language drill are much less suited to this purpose than those of a more general training that gives greatest weight to a sharpening of one's own powers of reflection".

- "The temple of science is a complex structure of many parts. Not only are the inmates diverse in nature, but so also are the inner forces that they have introduced into the temple. Many a one among them is engaged in science with a happy feeling of a superior mind, and finds science the sport which is congenial to him, and which is to give him an outlet for his strong life-forces and to bring him the realization of his ambitions. There are, indeed many, too, who offer up their sacrifice of brain-matter only in the cause useful achievements. If now, an angel of heaven were to come and expel all from the temple who belong to these two categories, a considerable reduction would result, but there would still remain within the temple men of present and former times: among these we count our Planck, and that is why he has our warm affection".

- "An experiment that verifies absolutely is impossible in Physics".

In a letter to James Franck, his German friend, Einstein wrote:

- "I can imagine that God created a world without any laws of nature. A chaos, in short. But the notion that statistical laws are final and that God draws lots is highly unsympathetic to me".

Regarding questions about verification of result by observation and experiment such as the one pertaining to the planet Mercury and the disagreement of actual calculations with reality and the question of getting upset over results which do not agree with theory, Einstein replied:

- "Such questions did not lie in my path. That result could not be otherwise than right. I was only concerned in putting the result in a lucid form. I did not for one second doubt that it would agree with observation. There was no sense in getting excited about what was self-evident".

- "Discovery is really not a creative act".

- "Without the belief that it is possible to grasp the reality with our theoretical constructions and without the belief in the inner harmony of our world, there could be no science. This belief is and always will remain the fundamental motive for all scientific creation. Throughout all our efforts, in every dramatic struggle between old and new views, we recognize the eternal longing for understanding the ever firm belief in the harmony of our world".

Einstein wrote addressing himself to Newton:

- "You found the only way which, in your age, was just about possible..........." But these words follow several pages of quite contemporary discussions with Newton on quite contemporary problems, and it begins with the personal address: "Newton, forgive me"

- "A genius is one to whom ideas occur"

- "An idea is not a thought: a thought knows its bounds, whereas the idea leaps over them and succeeds in accomplishing nothing".

Once an intrusive visitor - of whom Einstein had so many - asked him: How on your death-bed, would you answer the question whether your life was successful or in vain? As usual Einstein paid no attention to the tactlessness of the question and replied with characteristic simplicity:

- "I would not be interested in such a question either in my death-bed or at any other time. After all I am only a tiny particle of nature".

Einstein once said in a chat with Infeld:

- "Life is an exciting show. I enjoy it. It is wonderful. But if I knew that I should have to die in three hours it would impress me very little. I should think how best to use the last three hours than quietly order my papers and lie peacefully down".

- "A candidate for the teaching profession, who in the early stages of his academic career fails to show his fitness, his individual facultas docendi, should be removed from the university".

- "A proposition is correct, if, within a logical system it is deduced according to the accepted logical rules. A system has truth content according to the certainty and completeness of its coordination possibility to the totality of experience". 
In his Oxford lecture in 1920, Einstein spoke:

- "It is my conviction that pure mathematical construction enables us to discover the concepts and the laws connecting them, which gave us the key to the understanding of the phenomena of nature. Experience can, of course, guide us in our choice of serviceable mathematical concepts, it cannot possibly the source from which they are derived. In a certain sense, therefore, I hold it to be true that pure thought is competent to comprehend the real as the ancients dreamed".

- "All knowledge of reality starts from experience and ends in it".

In 1953, Einstein writes to one of his old friends:

- "Dogs and little children immediately recognize a kind person from a bad one, guided by their first impression, they confide to the former and keep away from the latter. As a rule, they are not mistaken, even though they do not apply scientific methods or systematic physiognomic studies in accumulating their small experience".

- "If experience is the alpha and omega of all knowledge, what is the function of pure reason?".

Einstein commends on Kepler's work as follows:

- 'Kepler's work was possible only when he succeeded in freeing himself to a great extent of the intellectual traditions into which he was born. This meant not merely the religious tradition, based on the authority of the church, but the general concepts of the nature and limitations of action within the universe and the human sphere as well as notions of the relative importance of thought and experience in science".

When the theory of relativity was called a creative act, Einstein replied thus:

- "By no means it is a creative act, for it is not true that this fundamental principle occurred to me as the primary thought. If this had been so perhaps it would be justifiable to call it a 'discovery'. I deny the suddenness with which it is assumed to have a occurred to me. Actually, I was led to it by steps arising from the individual laws derived from experience".

A few years before his death, Einstein wrote to his friend Max Born, a 1954 Nobel Prize winner for his statistical interpretation of wave function in Quantum Mechanics:

- " $\ldots . . . \ldots . . . .$. Liberation from the bondage of self constitutes the only way towards the more satisfactory human society............. I simply enjoy giving more than receiving.......... Many people are like this and I really cannot understand why I have been made into a kind of idol".

Einstein proclaims that:

- "Science is its own subject, Science for its own sake; it carries its aims absolutely in itself and must not through aiming at other purposes, stray from its own highways".

He says that:

- "It is my inner conviction that the development of science itself seeks in the main to satisfy the longing for pure knowledge which, psychologically, asserts itself as religious feeling".

This was what Einstein said on 'Education' and 'Teaching':

- "It is a miracle that curiosity survives formal education

- "I never teach my pupils. I only attempt to provide the condition in which they can learn".

- "Most teachers waste their time by asking questions that are intended to discover what a pupil does not know, whereas the true art of questioning is to discover what the pupil does know or capable of knowing".

- "Education is what remains after one has forgotten what one learned in school".

Einstein further says:

- "I never came upon any of my discoveries through the process of rational thinking".

- "Only a life lived for others is a life worthwhile. It is high time that the ideal of success should be replaced by the ideal of service".

- "The whole of science is nothing more than a refinement of everyday thinking".

- "The most beautiful experience we can have is the mysterious. It is the fundamental emotion which stands at the cradle of true art and true science".

- "When I examined myself and my methods of thought, I came to the conclusion that the gift of fantasy has meant more to me than my talent for absorbing positive knowledge".

- "Nationalism is an infantile disease, the measles of mankind".

- "A problem cannot be solved with the same consciousness that created it". 
- "Weakness of attitude becomes weakness of character".

- "A human being is part of the whole that we call the universe, a part limited in time and space. He experiences himself, his thoughts and feelings, as something separated from the rest - a kind of optical illusion of his consciousness. This illusion is a prison for us, restricting to our personal desires and to affection for only the few people nearest us. Our task must be to free ourselves from this prison by widening our circle of compassion to embrace all living things and all of nature".

- "Imagination is more important than knowledge; Knowledge is limited; Imagination encircles the world".

- "In order to form an immaculate number of a sheep, lone must, above all, become a sheep".

- "Anger dwells only in the bosom of fools".

- "There are only two ways to live your life. One is as though nothing is a miracle. The other is as though everything is a miracle".

- "No amount of experimentation can ever prove me right. A single experiment can prove me wrong".

On the fission of Plutonium for the preparation of nuclear weapons and on the second World War, Einstein said:

- "Science can denature Plutonium, but it cannot denature evil in the heart of man. So, there must be another dimension to science truth seeking".

- "I know not with what weapons World War II will be fought, but World War IV will be fought with sticks and stones".

Einstein used to be very witty and humorous many times and explains the theory of relativity to Benjamin Fine, a leading authority on Education and winner of the Pulitzer Prize in 1944 on behalf of New York Times:

- "Everything is relative, said Einstein. If you sit on a hot stove for one minute, it will seem like one hour. But, if a pretty girl sits on your lap for one hour, it will seem like one minute".

- "I never think of future, it comes soon enough".

- "The man who regards his own life and that of his fellow creatures as meaningless, is disqualified for life".

- "The world is a dangerous place, not because of those who do evil, but because of those who look on and do nothing".

- "Two things are infinite. The universe and human stupidity and I am not sure about the universe".

- "Falling in love is not at all the most stupid thing that people do, but gravitation cannot be held responsible for it".

- "Intellectuals solve problems, but geniuses prevent them".

After the destruction created by the bombing of Hiroshima during the second World War, Einstein sadly remarked:

- "If only I had known, I should have become a watchmaker".

- "If A is success in life, then A equals $\mathrm{X}+\mathrm{Y}+\mathrm{Z}$. $\mathrm{X}$ is work, $\mathrm{Y}$ is play and $\mathrm{Z}$ is keeping your mouth shut".

The relation between photon hypothesis and Planck's theory was expressed by Einstein in the following way:

- "Even though beer is always sold in pint bottles, it does not follow that beer consists of invisible pint portions".

In the year 1919, Einstein's 9 year old son, Edward asked him: Daddy, why are you so famous?

Einstein laughed and explained quite seriously:

- "You see, son, when a blind bug crawls along the surface of a sphere, it does not notice that its path is curved. I was fortunate enough to notice this".

Einstein received almost everyday enormous quantity of mail due to which he once remarked:

- "The postman is my greatest enemy. I shall never escape from his clutches".

Einstein at Leisure:

- "I like sailing because it is the sport which demands the least energy".

- "As far as the laws of Mathematics refer to reality, they are not certain; and as far as they are certain, they do not refer to reality"

On the death by assassination of Mahatma Gandhi, the father of the Indian nation, Einstein said:

- "No one will believe that a man like this with body and soul ever walked on this Earth".

In the following, I shall give some of the words of appreciation on Einstein by some eminent men:

The Russian author, B Kuznetsov, who has written a book titled 'Einstein' says in the introductory chapter:

- "In the $20^{\text {th }}$ century a scientist can achieve the highest repute ('A man, take him for all in all') if he propounds a theory severing as drastically, if not more so, with dogmas and dogmatic 'self evidence' 


\section{International Advanced Research Journal in Science, Engineering and Technology}

ISO 3297:2007 Certified

Vol. 4, Issue 9, September 2017

The great physicist, Max Planck, who discovered the 'Quantum' said that:

- "A genius has come into Physics, the kind of which can appear only once in a century".

When the mathematician, Littlewood explained the theory of relativity to Bertrand Russell, he said he had spent his own life on muck.

Sir J J Thomson, the 1906 Nobel Prize winner for his work on discharge of electricity through gases, said:

- "I have to confess that no one has yet succeeded in stating in clear language what the theory of Einstein really is?"

Einstein for the first time visited United State on 3 April 1921 the same year when he received the Nobel Prize for the discovery of the Photoelectric Effect. In Fig.15 is seen Einstein is being received and taken on 4 April 1921 in the streets of New York.

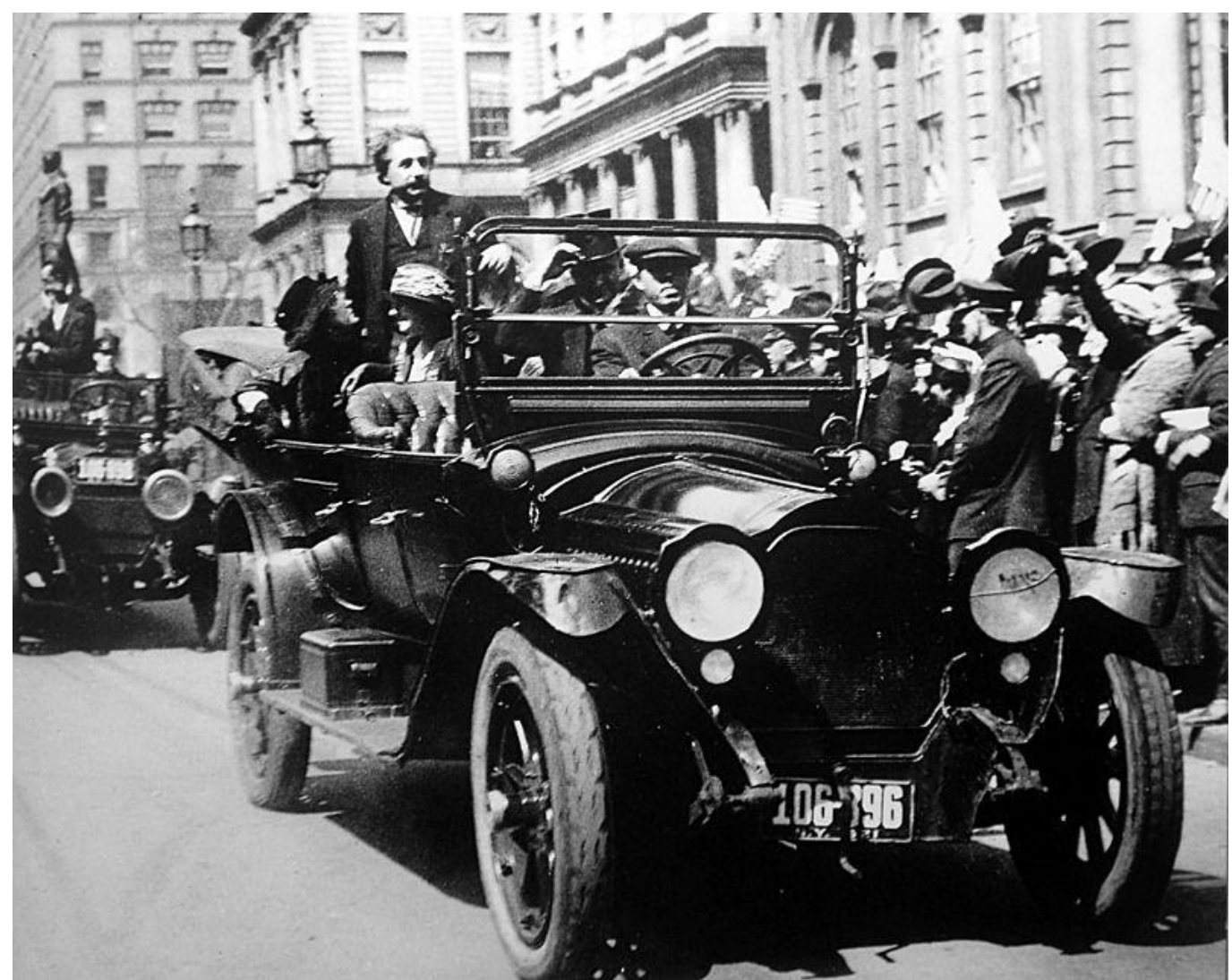

Fig. 15 The motorcade in New York City, 4 April 1921

In 1933 when Adolf Hitler became the Chancellor of Germany, Einstein who was of Jewish parentage was deprived of both his German citizenship and the professorship he held at the University of Berlin. Hence he went back to US for the second time and was made professor of Mathematical Physics at the Institute of Advanced Study in Princeton, New Jersey, US and got established himself at a house in 112 Mercer Street, Princeton, New Jersey (Fig.28). In 1940, he was sworn in as the citizen of United States and worked in Princeton University till his death in 1955.

His last theory was an attempt to deal with electric, magnetic and gravitational fields as a single unified theory, what he called as the 'Theory of Everything', but with his death the world of Physics lost everything.

The name of one of the Indian scientists is closely associated with Einstein. He is prof. S.N. Bose of Calcutta University. There are two types of distributions in Quantum Statistics: They are: Fermi-Dirac Distribution and BoseEinstein Distribution. Bose and Einstein together worked on this Distribution which has been successfully applied in the explanation of black body radiation and gas degeneration.

As for the private life of Einstein, he married his own classmate Mileva (Fig.16) and had two sons. One became a hydraulic engineer who migrated to the United States. The other became mental and died young. Einstein never came to terms with Mileva and later divorced her and married his widowed cousin Elsa Lowenthal. (Fig.17). 
UGC Approved Journal

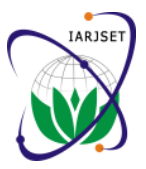

IARJSET

\section{International Advanced Research Journal in Science, Engineering and Technology}

ISO 3297:2007 Certified

Vol. 4, Issue 9, September 2017

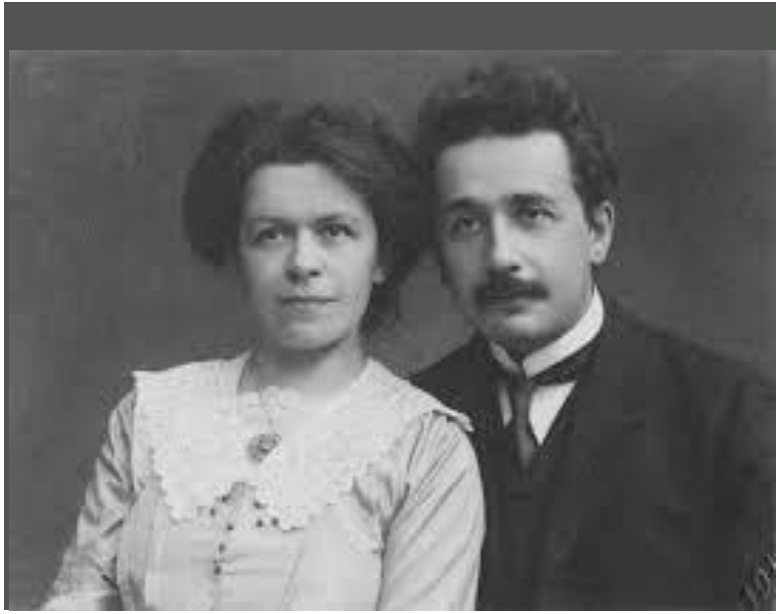

Fig. 16 Mileva Marie with Einstein (1905)

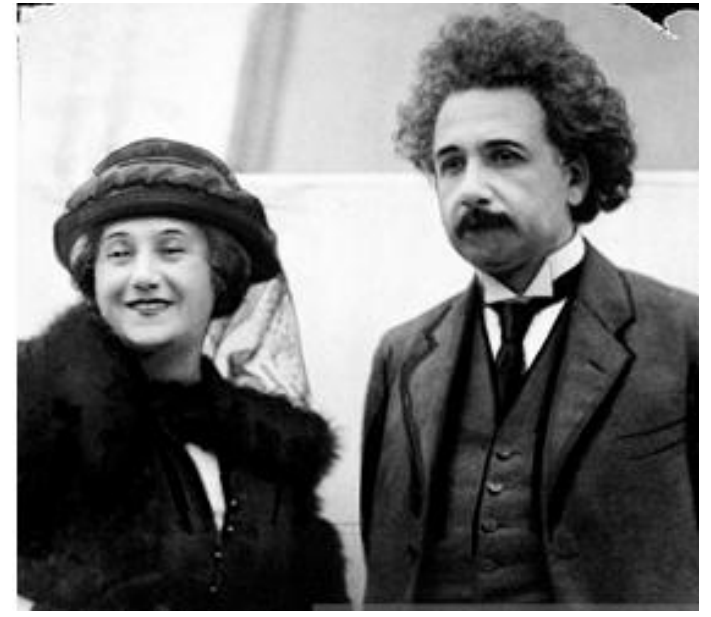

Fig.17 Elsa Loventhal with Einstein (1921)

Einstein loved music. At leisure he used to play violin (Fig. ) which he purchaed from Holland and carried the same wherever he went and played music to slow his frenetic brain process and help him relax.

Many world leaders and great personalities used to meet Einstein. The great Indian poet Rabindranath Tagore met Einstein (Fig.18)

- Einstein to Tagore:[6] "The problem begins whether the truth is independent of our consciousness" Mahatma Gandhi, the great freedom fighter and leader of the non-violent movement met Einstein (Fig.27). In Fig. 24 is shown Einstein with the first Indian Prime Minister, Jawaharlal Nehru.

As signature indicates the personality of an individual and to add quality to my Research Paper, I have included signatures of Einstein (Fig. 25)
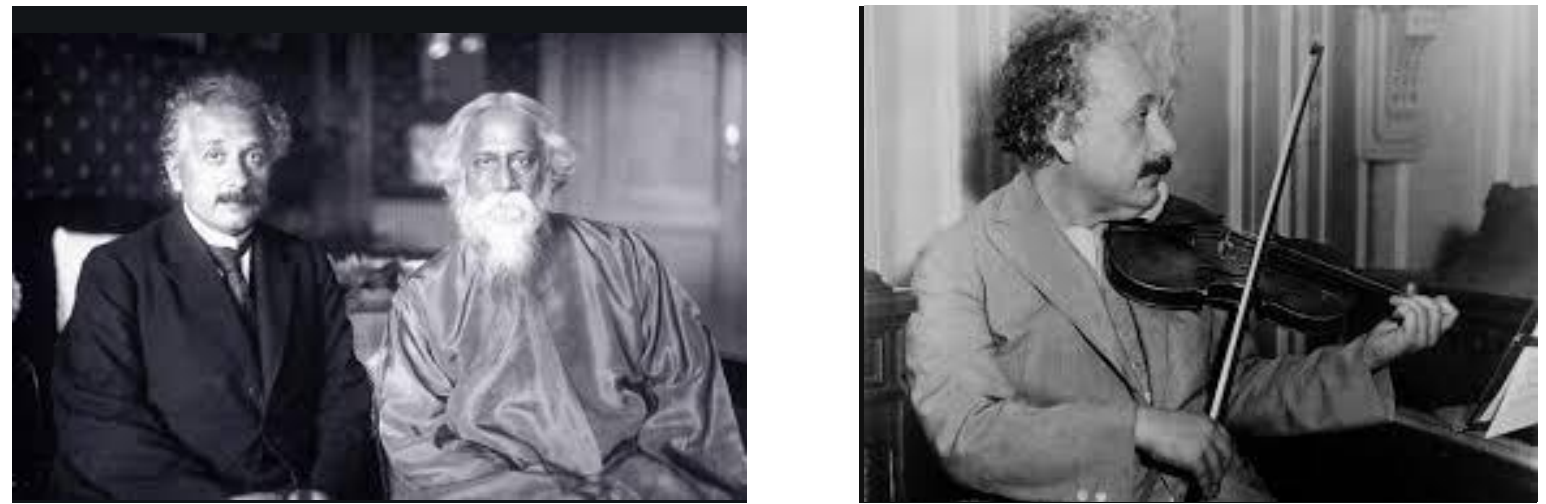

Fig.18 Einstein with great Indian poet Rabindranath Tagore (1861-1941) Fig.19 Einstein playing the violin
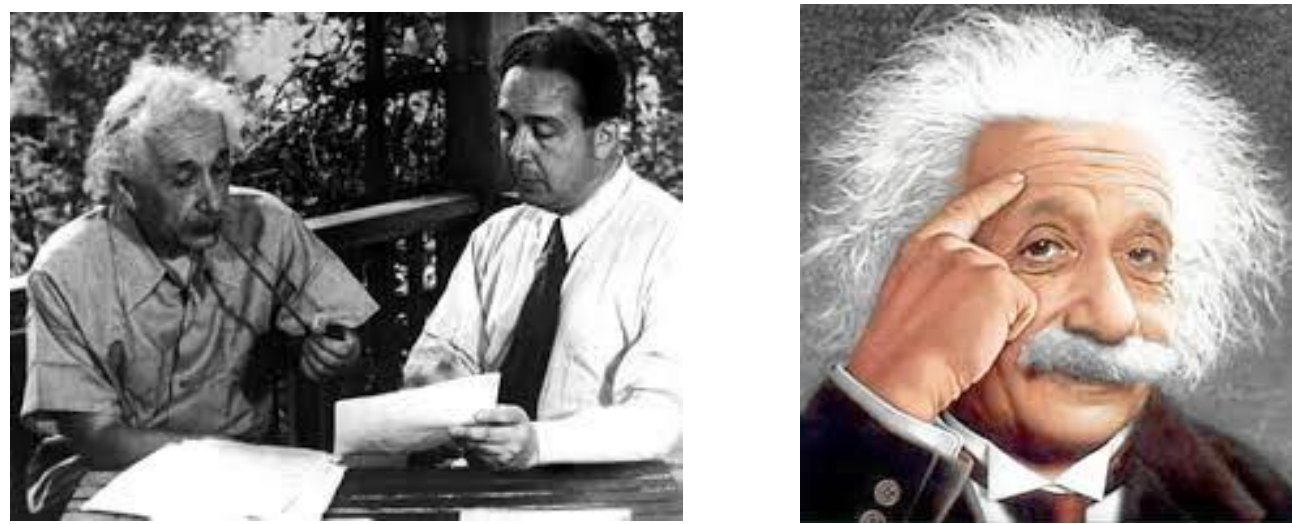

Fig.20 Physicist, Leo Szilard (1898-1964) showing Fig.21 Einstein for whom "Thinking is Worship" Something important to Einstein during World (A caricature showing importance of "Thinking")

War II (Photo reenacted in 1946) 
UGC Approved Journal

IARJSET
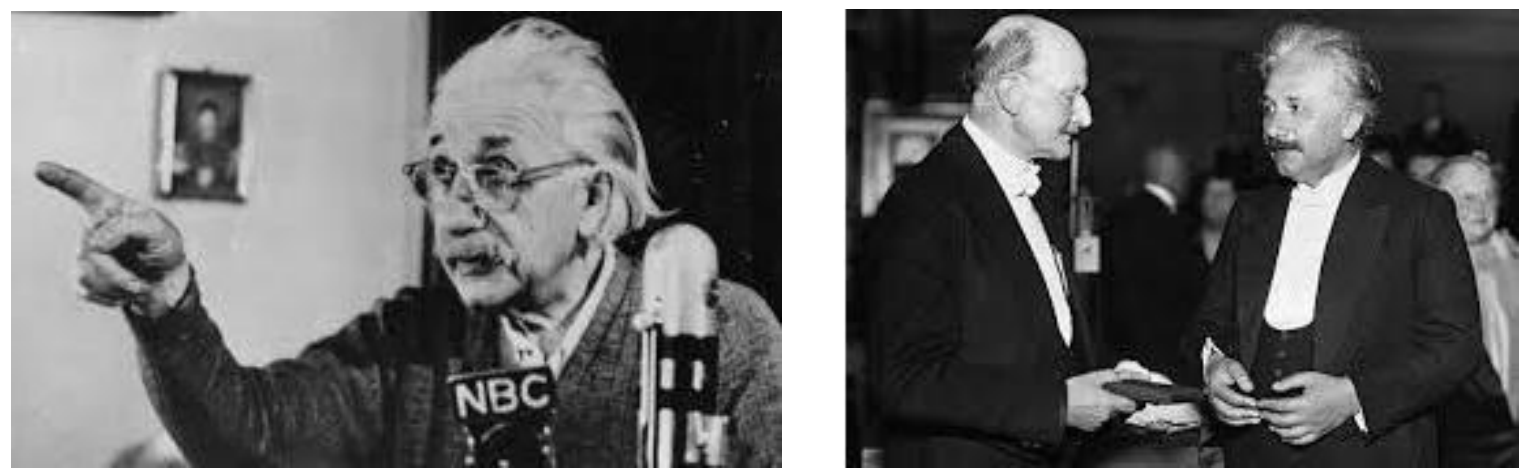

Fig.22 Einstein stressing a point at a press meeting Fig, 23 The two giants of Modern Physics Max Planck (Left) awarding the Max Planck Medal to Einstein (1929)

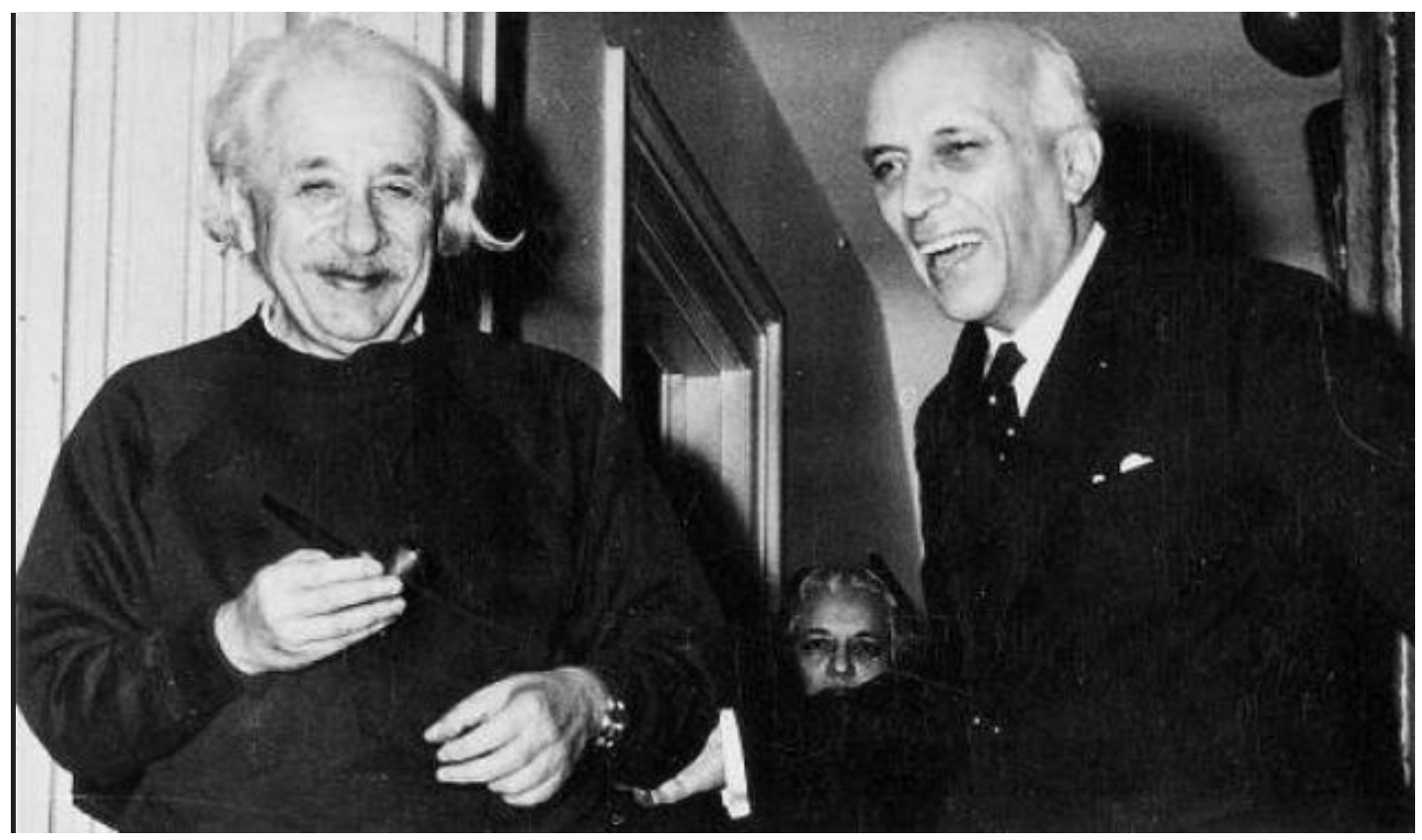

Fig.24 Einstein with Pundit Jawaharlal Nehru (1889-1964) the first Prime Minister of India
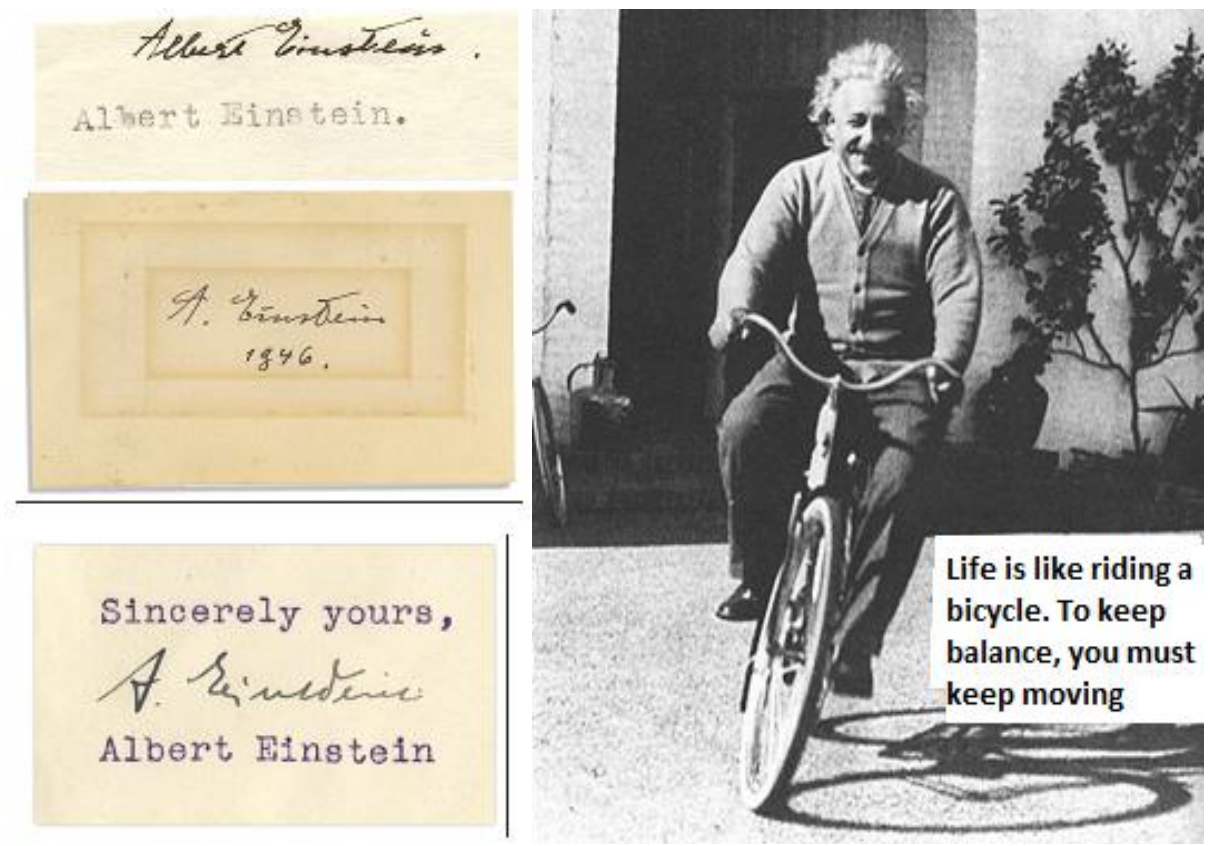

Fig.25 Signatures of Albert Einstein [8]

Fig 26. Bicycling in California, US, February 1933 
UGC Approved Journal

IARJSET

ISO 3297:2007 Certified

Vol. 4, Issue 9, September 2017

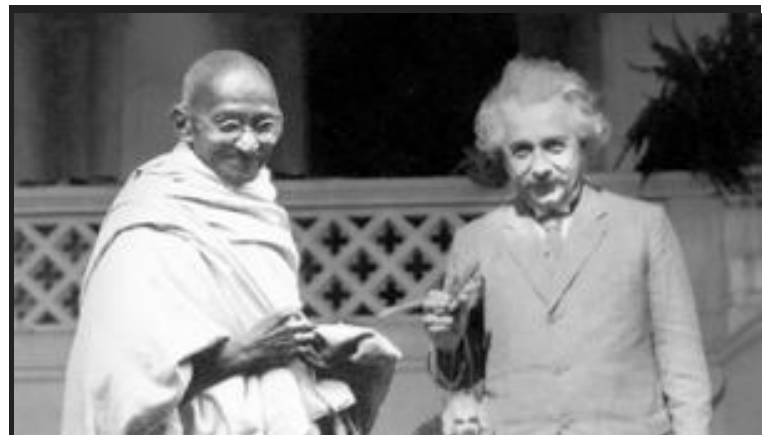

Fig 27. Mahatma Gandhi (1869-1948) with Einstein

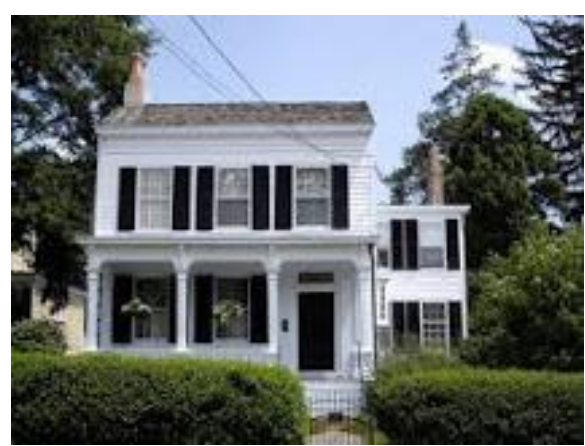

Fig.28 Einstein's residence at Princeton

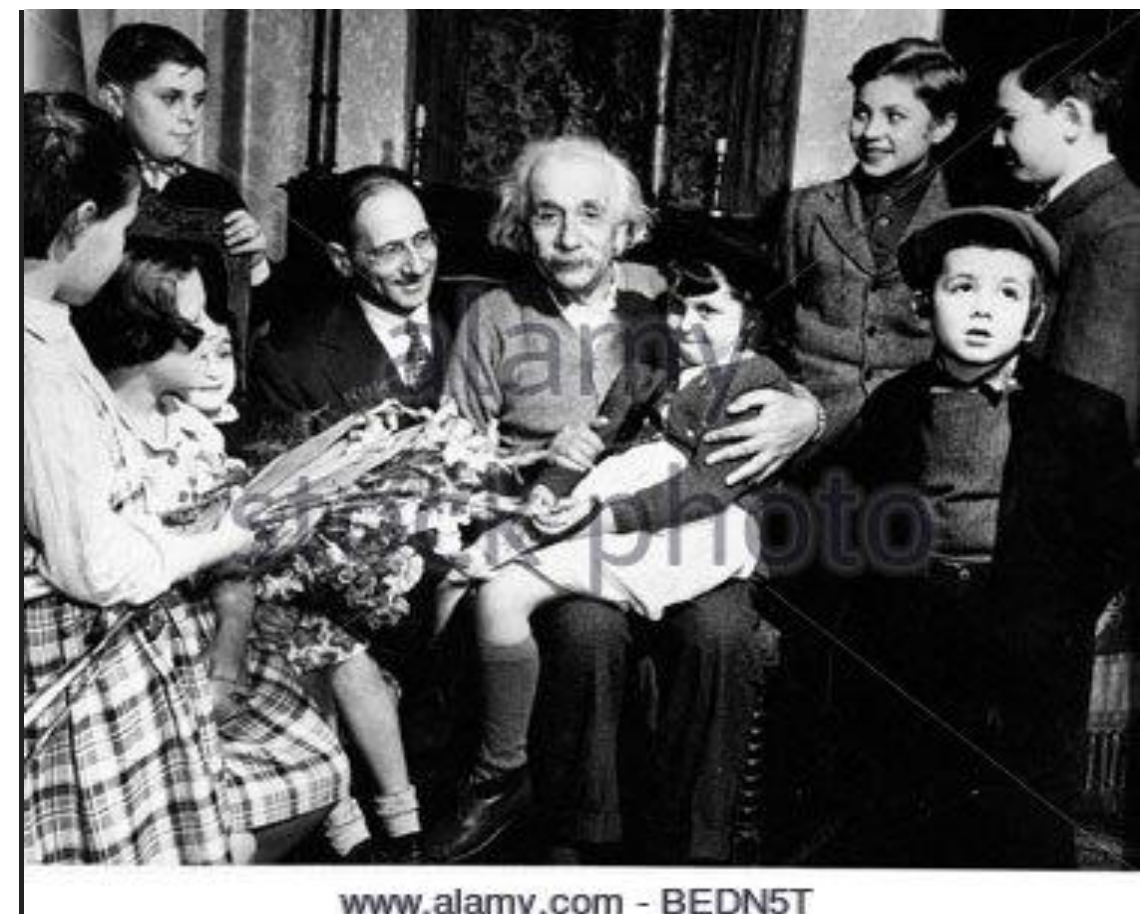

Fig.29 Einstein loved children, A photo taken on his $70^{\text {th }}$ Birth Day

On 13 April 1955 Einstein fell sick due to inflammation of the gall bladder and got admitted to a hospital on 15 April 1955 at Princeton. (Fig.30). An operation suggested by hospital doctors was refused by Einstein and he died at 1.25 AM on 18 April 1955 and the post mortem report revealed aortic haemorrhage of the abdomen.

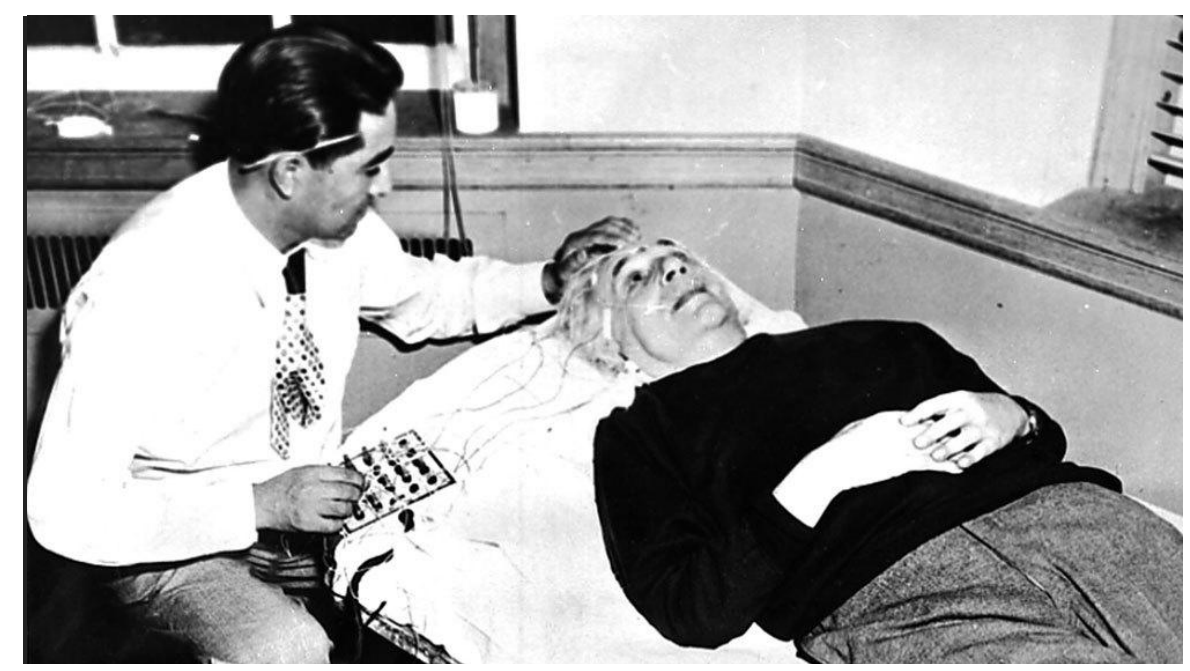

Fig. 30 Einstein being attended by doctor 
Einstein's will was read in the morning. His request was that his funeral be held without religious rites or official ceremony. The time and place of the funeral was kept secret from all except few friends, who saw his body to the crematorium. Ralph Morse, a photographer of LIFE Magazine took a large number of photographs of various events that took place till the end of cremation

The shocking news of the death of Einstein, a great scientist and people who considered him as a citizen of the world, was published in the morning of 18 April 1955 by the New York World-Telegram, "The Sun" (Fig.31). Einstein died in harness as seen from the picture (Fig.32) taken by Ralph Morse after few hours of his death at his residence in Princeton. Books, papers and files lie haphazard on table; some scribbled matter on blackboard and from the look of the picture, it appears, he has left lot of work unfinished.

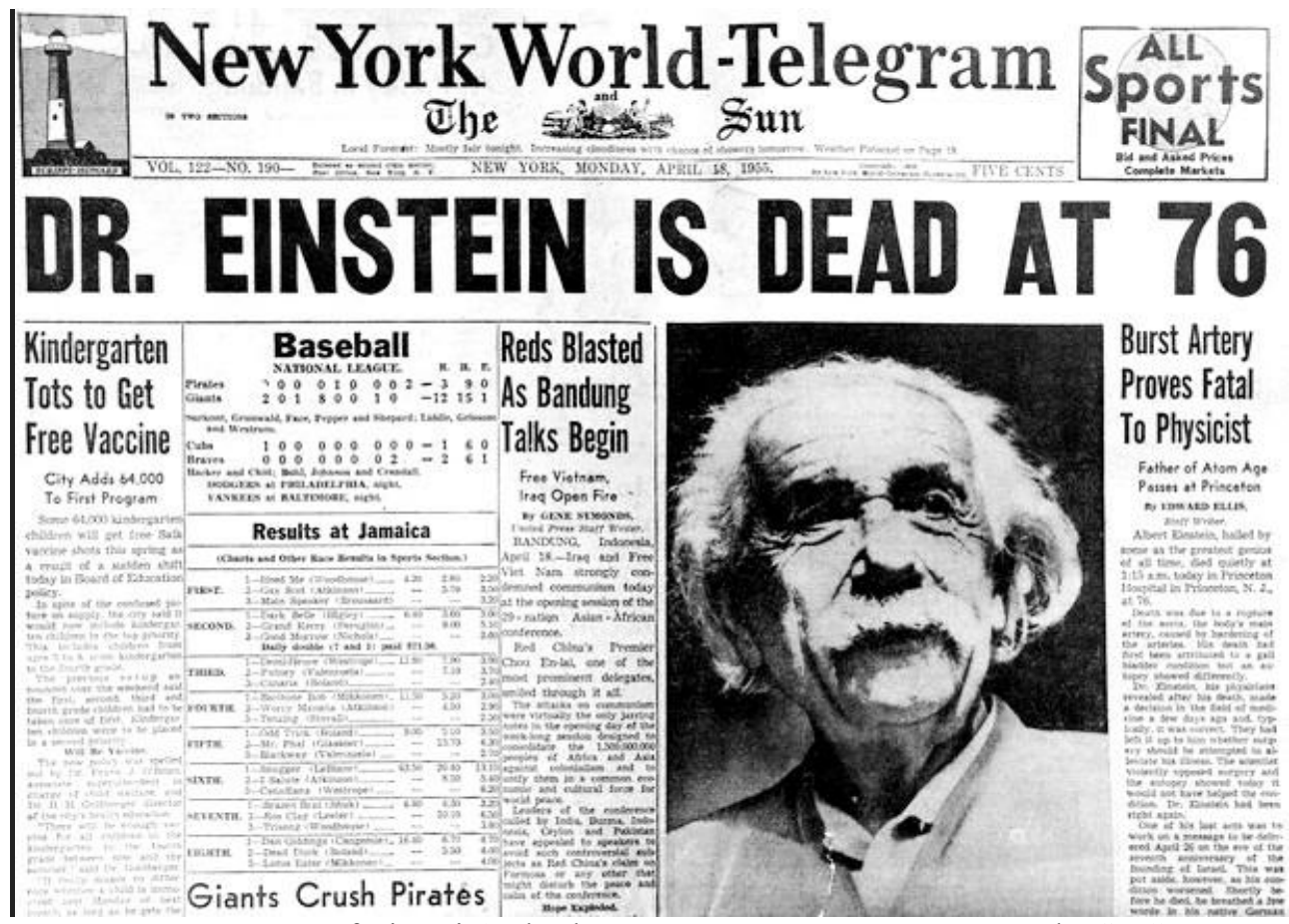

Fig.31 News of Einstein's death New York World Telegram - "The Sun"

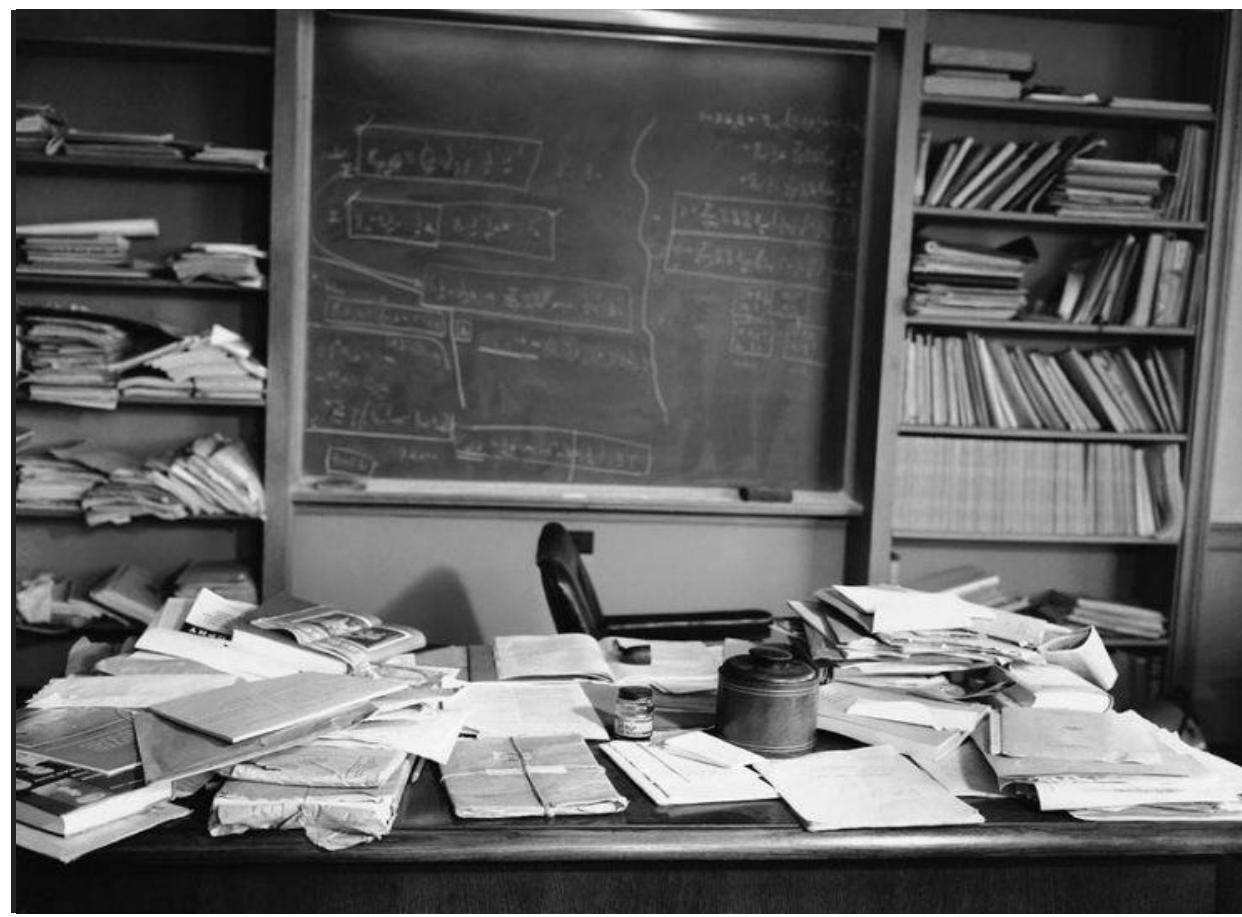

Fig.32 Einstein's Study Room at his residence when he fell sick and admitted to hospital 
UGC Approved Journal

\section{IARJSET}

\section{International Advanced Research Journal in Science, Engineering and Technology}

ISO 3297:2007 Certified

Vol. 4, Issue 9, September 2017

According to Robert Clark, his biographer Einstein had insisted that his brain should be used for research while the rest of the body could be cremated. As he left no written instructions for the disposal of his body, his son Prof. Hans Einstein gave permission for his father's brain to be removed for scientific study.

A team of brain specialists under the leadership of Dr. Thomas Harvey (Fig..33) the chief pathologist of the Princeton hospital carried out a detailed study of the brain. As the brain looked the same (Fig.34) as any other human brain except that it weighed slightly less $2.7 \mathrm{lb}$ as compared to $3.0 \mathrm{lb}$ of a normal brain and the lateral sulcus truncated, it was kept with due care in the Princeton hospital for further study.

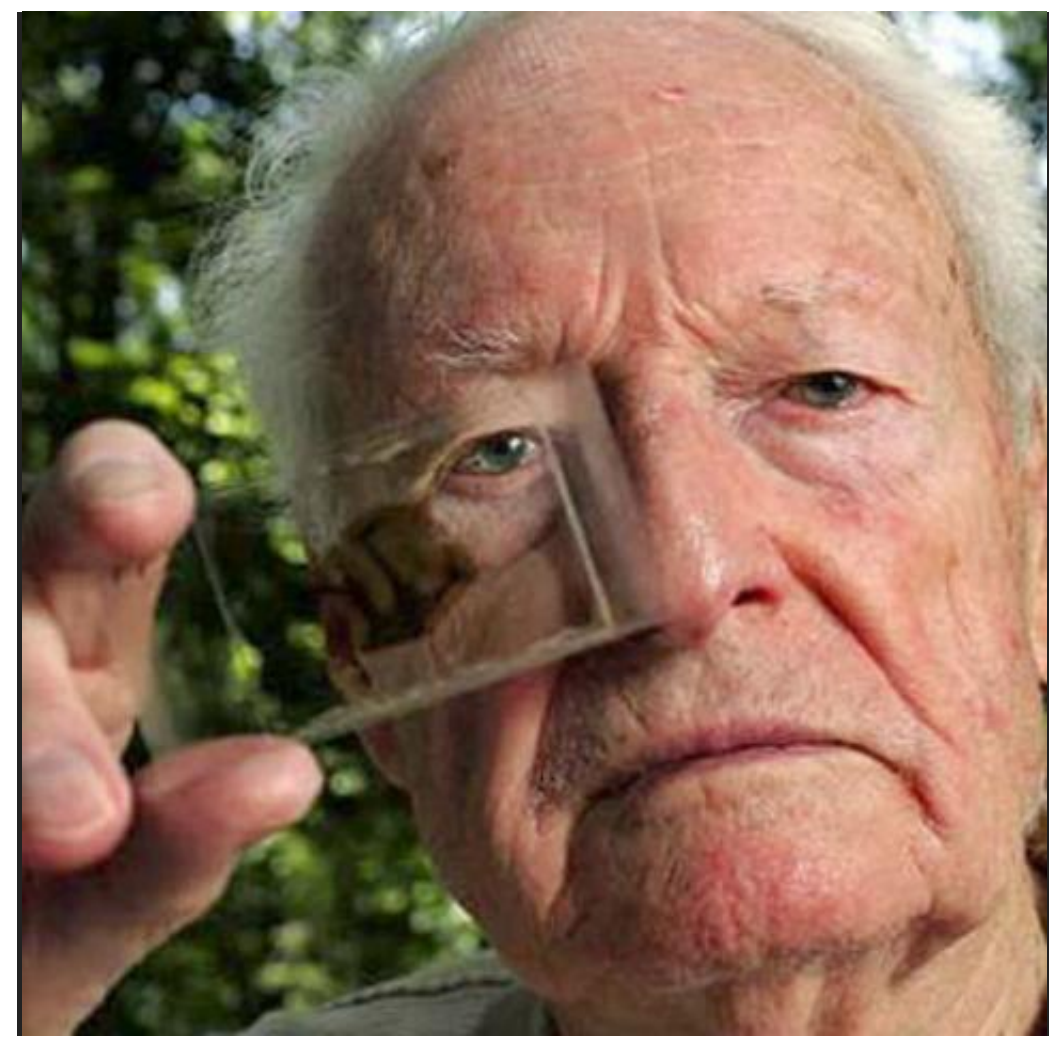

Fig. 33 Dr. Thomas Harvey, the Chief Pathologist at Princeton Hospital

\section{TYPICAL BRAIN}

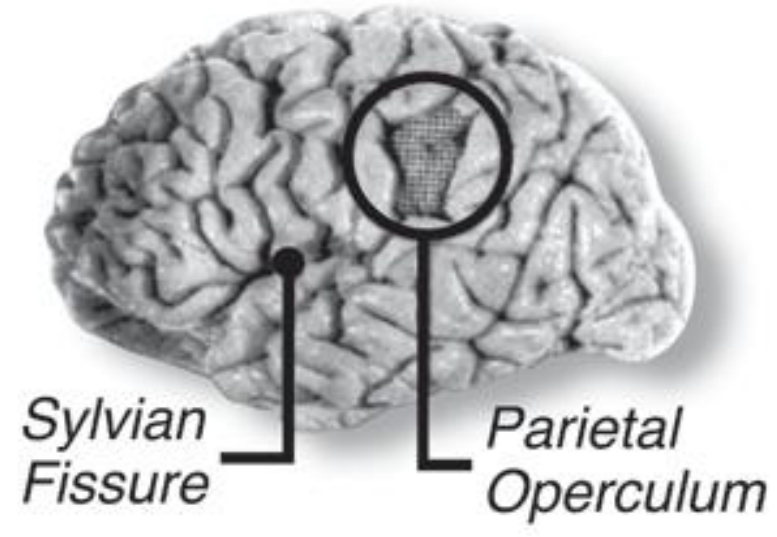

EINSTEIN'S BRAIN

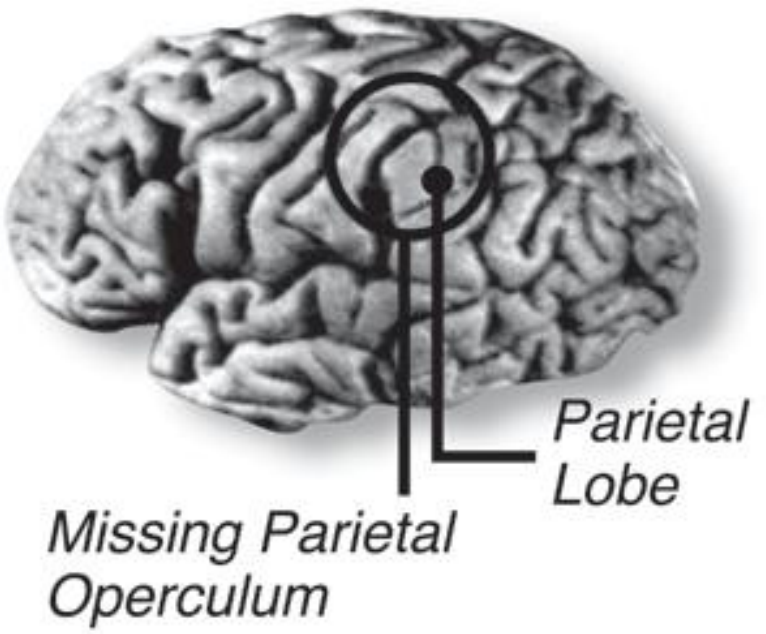

The lateral Sulcus (Sylvian Fissure) in a typical brain was truncated in Einstein's brain

Fig 34. Typical Brain in comparison with Einstein's Brain 
Further study of the brain was taken over in 1978 and pathologists and experts world over could not detect anything particular and the dissected pieces of the brain is now lying in Mutter Museun in Philadelphia, US. (Fig 35)

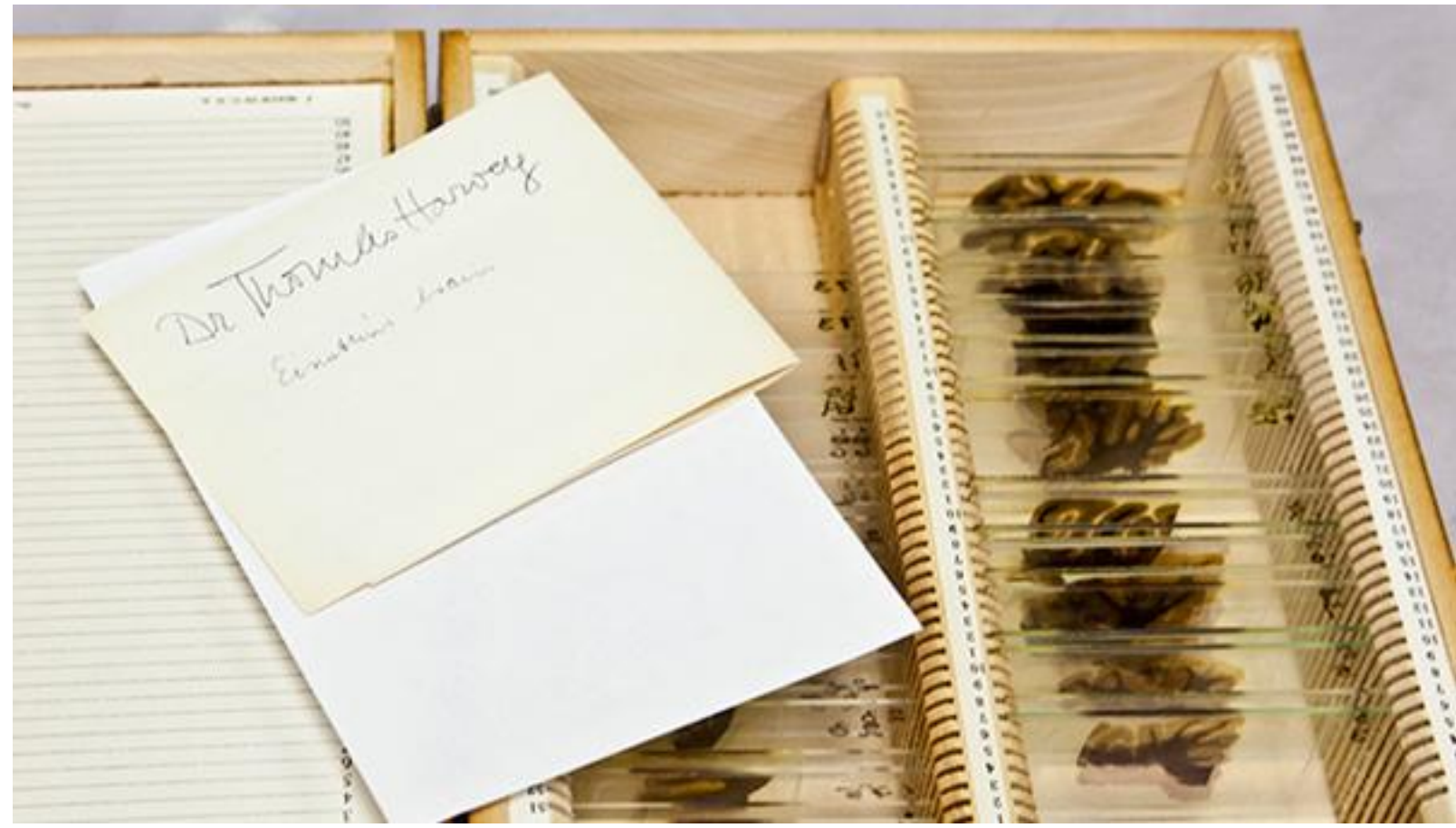

Fig. 35 The dissected parts of Einstein's brain lying at Mutter Museun

Einstein's legacy of genius endures in the work of the Hebrew University of Jerusalem. On the occasion of the founding of the Hebrew University of Jerusalem, Einstein said: "A University is a place where the universality of the human spirit manifests itself. Our University (the Hebrew University of Jerusalem) will develop speedily into a great spiritual center which will evoke the respect of cultural mankind the world over". He would later add to that sentiment at press event which recorded Einstein speaking his belief that "This institution of research and scholarship represents a spiritual bond encompassing the Jews in all countries".

\section{CONCLUSION}

The readers, after going through my lengthy paper might feel inclined to ask a question: If Einstein's theories specially that on gravitation is so complicated, if the cosmological conclusions from it to a large extent preliminary and often of a fantastic nature, and finally this theory has not helped to construct a single machine and has done nothing for technology as such, then what is that compels the greatest thinkers of today to regard it as the "Most remarkable achievement of the human mind".drawing the attention of physicists, philosophers, astronomers, etc. for over half a century? The point is that this was a discovery of unusually new and involved physical relationships which students of nature have never even suspected. With the help of Einstein's theory, we have entered a new field of unparalleled interest to humanity. Here, for the first time in an exact physical theory we are closer to an understanding of the infinite. Man, for the first time, began to feel the pulse of the universe not in the form of poetical revelations but via precise knowledge. Without Einstein's theory, most of the questions just discussed could not have been posed.

Any scientific theory is a certain approximation to reality. Einstein's theory is a deeper reflection to reality. No matter what heights of our subsequent understanding of gravitation may reach, the genius of this "Newton of the 20 th Century" and the incomparable audacity with which he refashioned our picture of the world will ever remain a great step forward in the cognition of nature. Einstein not only altered a scientific discipline, Physics, but also helped to alter the very way in which man viewed nature.

\section{ACKNOWLEDGEMENT}

I would like to very importantly acknowledge the work of B.Kuznetsev in his famous book on "Albert Einstein" translated from the Russian by V. TALMY, designed by V. AN and published by Progress Publishers, Moscow with the first printing appeared in 1965. Kuznetsev has dealt extensively with the life and times of the scientist giving a vivid exposition of Einstein's interaction with many scientists of his times. 


\section{International Advanced Research Journal in Science, Engineering and Technology}

ISO 3297:2007 Certified

Vol. 4, Issue 9, September 2017

Most of the matter presented in this Research Paper are excerpts from this book for which I offer my sincere thanks to the author.

"Wikipedia" is another great source of information which the author has gathered and a biggest thanks for that website.

\section{EPILOGUE}

I had the desire of just seeing the great physicist who created the equation, $\mathrm{E}=\mathrm{m} \mathrm{c}^{2}$ but it was too late. I was hardly 16 a student in SSC when Einstein died on 18 April 1955. Those times, not knowing what a nuclear bomb is, and as only a decade had passed after the bombings on Japan the idea of the bombs dropped in Japan was afresh in my mind and even people blaming Einstein for that. After a very long period of many years, sometime in the year 2007, I travelled to Princeton, New Jersey, US from India almost like a pilgrimage and visited the famous University of Princeton where the great scientist spent more than 25 years of his time in research. On another occasion during the visit to the US in 2009, I was at the Discovery Center which is a part of the Lawrence Livermore National Laboratory at Livermore, California wherein I saw a life-size PORTRAIT of the scientist looking lively and as if explaining "What is Physics?" a legible note on a board kept at the right side of the portrait. With permission a photograph was taken with me and the portrait with the note at the center. (See Fig.36)

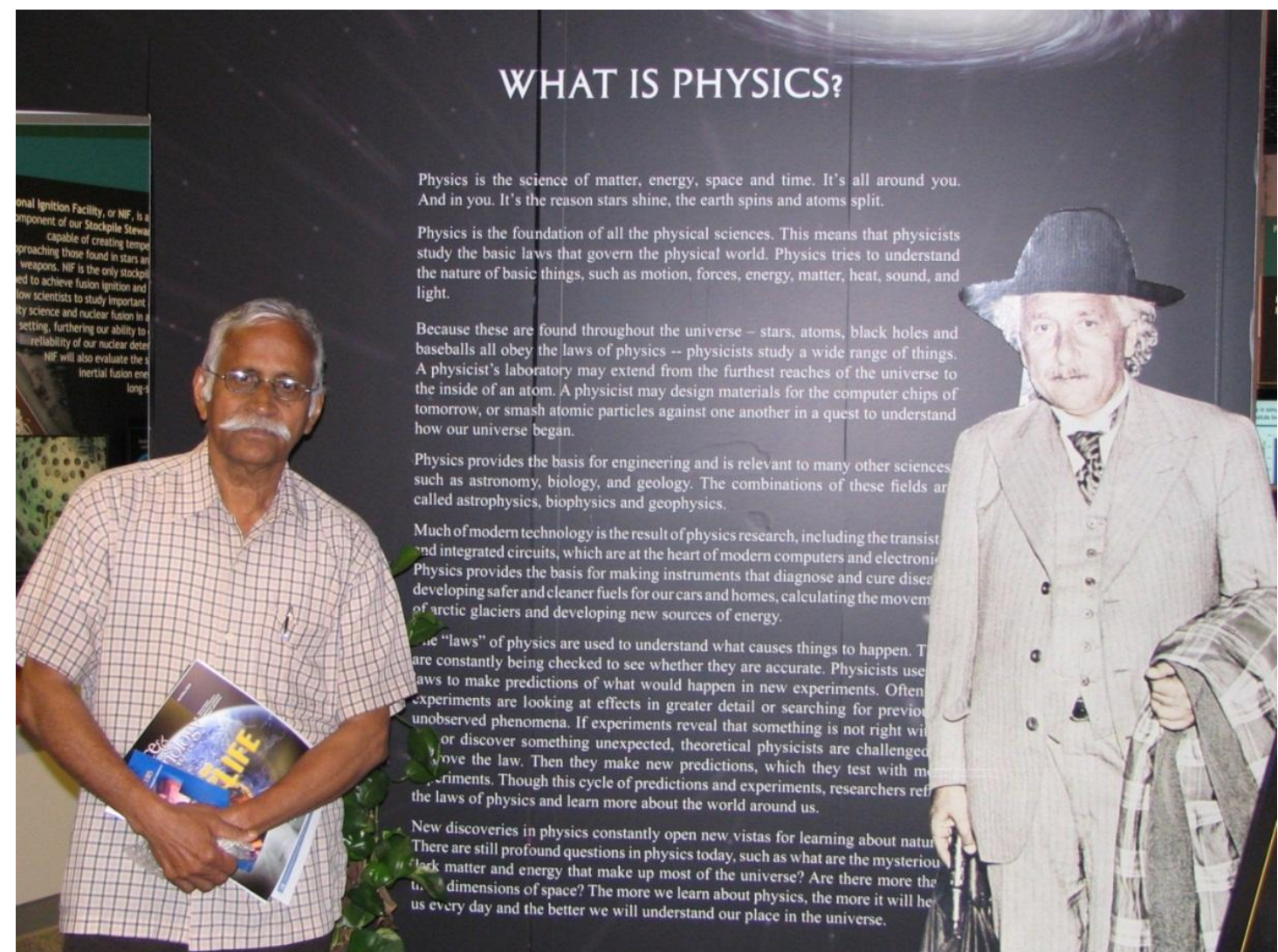

Fig.36 Prof. V.C.A. Nair standing near a PORTRAIT of Dr. Albert Einstein, the great theoretical Physicist at "Discovery Center", Lawrence Livermore National Laboratory, Livermore, California, USA, 9 ${ }^{\text {th }}$ July 2009.

\section{Personal note to readers:}

If any reader wants to have a further glimpse of the scientist by way of seeing a portrait (Pencil sketch, about 2 feet by $1 \frac{1}{2}$ feet and exclusively drawn by the author) and a colored solid marble bust ( $2 \times 1$ foot size) got it made and plenty of literature on Einstein kept at his house in Mumbai, India as a monument. Anybody interested can contact me by my e-mail: nairvca39@gmail.com.

\section{REFERENCES}

[1] Chris Pollock, Mercury's Perihelion, March 31, 2003, www.math.toronto.edu

[2] Christian Magnan, Deviation of Light near the Sun in General Relativity, 2007-01-09

[3] Don Edwards, Gravitational Bending of Light, March 24, 2007 
UGC Approved Journal

[4] Joel Brown, 55 Mind Blowing Quotes, Feb. 3, 2016.

[5] Kuznetsev B, “Albert Einstein" translated from the Russian by V. TALMY, designed by V. AN and published by Progress Publishers, Moscow with the first printing appeared in 1965.

[6] Maria Popova, Bulgarian writer, When Einstein met Tagore: A Remarkable Meeting of Minds on the Edge of Science and Spirituality

[7] Rajam J.B., Atomic Physics, $4^{\text {th }}$.Ed. 1958, S.Chand \& Co., Einstein's solution to the problem of Gravitation, p.374-378

[8] Zurich Manuscripts.

Zurich Manuscripts

Chris Pollock, Mercury's Perihelion, www.math.toronto.edu, March 31, 2003

\section{BIOGRAPHY}

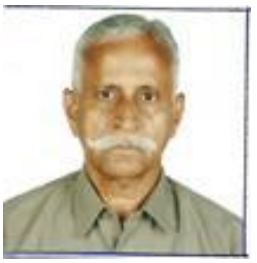

Dr. (Prof.) V.C.A. Nair (b.15th Aug. 1939) is an Educational Physicist, Counselor, Research Guide and Consultant. He did his Masters in Physics from Mumbai University, India and Ph.D. from JJT University, Rajasthan also in India He is a Research Guide and distinguished alumni of JJT University. He is also a Chancellor designated Resource Person in the area of Physics in the University. He has to his credit over 4 decades of teaching Applied Physics in eminent Polytechnics in Mumbai and having taught nearly 16,000 students since 1965. He has published a number of research papers in Physics and Geophysics in International and UGC recognized Journals some of which can be seen in the net 'Google Search' when the name of the author is typed in that style. He is a Life Member of Indian Society for Technical Education which is an all India body. He had been to USA a number of times and visited eminent Universities such as Stanford, Harvard, MIT, University of California both at Berkeley and Los Angeles and University of San Francisco. At present Dr. Nair is a Research Guide for Physics at JJT University, Rajasthan, India. His Ph.D. Thesis is in Geophysics and he is working on topics such as Tides, Clouds, Global Warming and Climate Change. - Editor.

*nairvca39@gmail.com. 